14th AIAA/AHI International Space Planes and Hypersonic Systems and Technologies Conference, 6-9 November 2006, Canberra, Australia

\title{
Orion Aerodynamics for Hypersonic Free Molecular to Continuum Conditions
}

\author{
James N. Moss,* \\ NASA Langley Research Center, Hampton, VA 23681-2199 \\ Katie A. Boyles, ${ }^{\dagger}$ \\ NASA Johnson Space Center, Houston, TX 77058-3696 \\ and \\ Francis A. Greene ${ }^{\ddagger}$ \\ NASA Langley Research Center, Hampton, VA 23681-2199
}

\begin{abstract}
Numerical simulations are performed for the Orion Crew Module, previously known as the Crew Exploration Vehicle (CEV) Command Module, to characterize its aerodynamics during the high altitude portion of its reentry into the Earth's atmosphere; that is, from free molecular to continuum hypersonic conditions. The focus is on flow conditions similar to those that the Orion Crew Module would experience during a return from the International Space Station. The bulk of the calculations are performed with two direct simulation Monte Carlo (DSMC) codes, and these data are anchored with results from both free molecular and Navier-Stokes calculations. Results for aerodynamic forces and moments are presented that demonstrate their sensitivity to rarefaction; that is, for free molecular to continuum conditions (Knudsen numbers of 111 to 0.0003 ). Also included are aerodynamic data as a function of angle of attack for different levels of rarefaction and results that demonstrate the aerodynamic sensitivity of the Orion CM to a range of reentry velocities (7.6 to 15 $\mathrm{km} / \mathrm{s})$.
\end{abstract}

\section{Nomenclature}

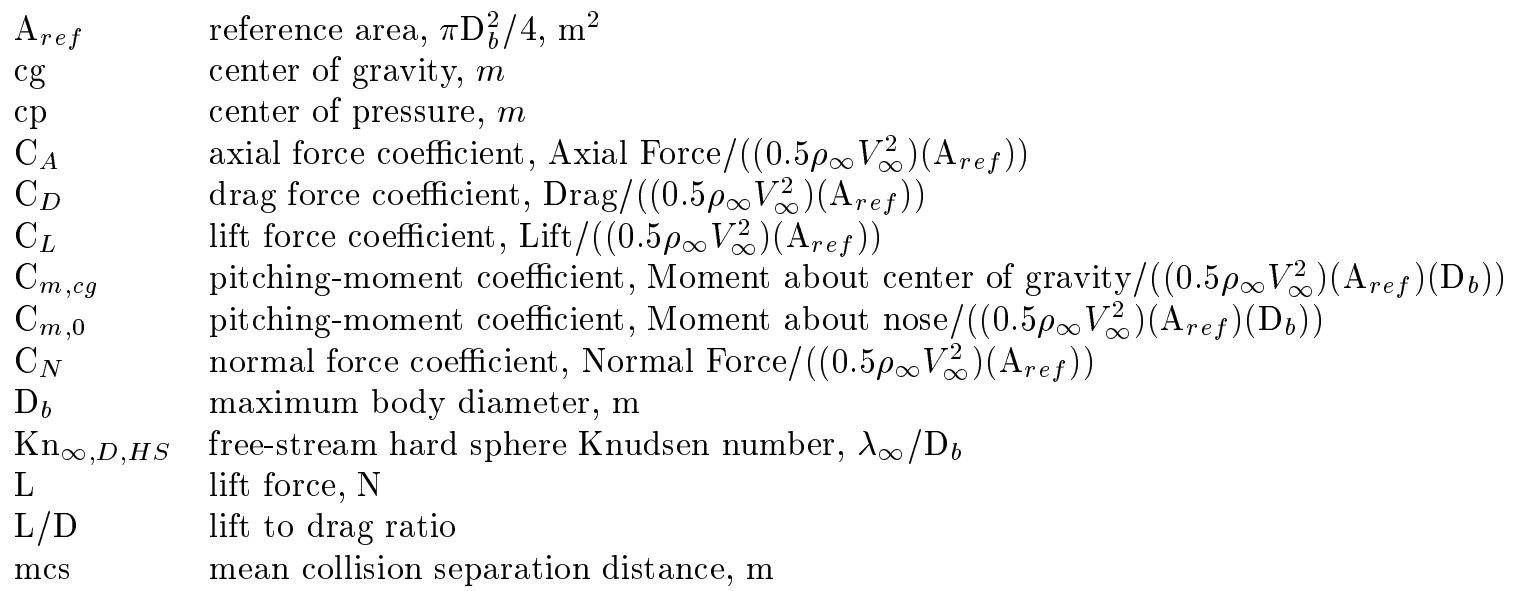

\footnotetext{
*Aerospace Engineer, Aerothermodynamics Branch, Mail Stop 408A, j.n.moss@larc.nasa.gov, Fellow AIAA.
}

$\dagger$ †erospace Engineer, Applied Aeroscience and CFD Branch, Mail Stop EG3, katie.a.boyles@nasa.gov, AIAA Member.

¥Aerospace Engineer, Aerothermodynamics Branch, Mail Stop 408A, f.a.greene@larc.nasa.gov, AIAA Senior Member.

This material is declared a work of the U.S. Government and is not subject to copyright protection in the United States.2006 


$\begin{array}{ll}\mathrm{mfp} & \text { mean free path, } \mathrm{m} \\ \mathrm{n} & \text { number density, } \mathrm{m}^{-3} \\ \mathrm{R}_{a} & \text { afterbody spherical nose radius }, \mathrm{m} \\ \mathrm{R}_{n} & \text { blunt forebody spherical nose radius , m } \\ \mathrm{R}_{s} & \text { shoulder radius }, \mathrm{m} \\ \mathrm{T} & \text { temperature, } \mathrm{K} \\ \mathrm{V}_{\infty} & \text { free-stream velocity, } \mathrm{m} / \mathrm{s} \\ \mathrm{x}, \mathrm{y}, \mathrm{z} & \text { model coordinates, } \mathrm{m} \\ \mathrm{X} & \text { mole fractions } \\ \alpha & \text { angle of incidence, deg } \\ \lambda_{\infty} & \text { mean free path in free stream, } \mathrm{m} \\ \rho & \text { density, kg/m } \mathrm{m}^{3}\end{array}$

\section{A. Subscripts}

W wall

$\infty \quad$ free stream

\section{Introduction}

Orion is a manned spacecraft (http://www.nasa.gov/mission_pages/constellation/orion/index.html), similar in shape to the Apollo Command Module (Fig. 1) and capable of holding four to six crew members, being developed by the United States to replace the Space Shuttle fleet after the last of the shuttles are retired. Until recently, it was known as the Crew Exploration Vehicle or CEV. Orion will be launched into Earth orbit by the Ares I rocket, capable of transporting cargo and up to six crew members to and from the International Space Station (ISS). It is also intended to support manned missions to the Moon and to Mars. Orion is one of several elements that comprises NASA's Project Constellation; other elements being the Earth Departure Stage (EDS), the Lunar Surface Access Module (LSAM), and the Ares I and Ares V Shuttle derived launch vehicles.

With commitments to evolve the Orion Crew Module (CM) design(s) for low Earth orbit (LEO), lunar, and Mars missions, aerothermodynamic data bases will be generated utilizing computational and experimental (both ground-based and flight) resources. These new data bases along with an extensive capsule heritage, particularly that from Apollo (Refs. 1 to 5, for example), will provide the basis for optimizing Orion's design, with particular emphasis on safety, flexibility, and affordability. The current study focuses on the aerodynamics of the Orion CM during the high altitude portion of its reentry; that is, for free molecular, transitional, and the higher altitude portion of the continuum regimes. The primary focus is on flow conditions similar to those that could be experienced by Orion during return from the ISS, at a reentry velocity of $7.6 \mathrm{~km} / \mathrm{s}$ and an angle of attack of $-26 \mathrm{deg}$. This study builds on the results and experience of recent studies ${ }^{6-8}$ for predicting the Apollo aerodynamics in the rarefied and continuum regime. Numerical simulations for the transitional flow regime are made with two DSMC codes: the code of Bird ${ }^{9-11}$ called DS3V, and the code of LeBeau, ${ }^{12-14}$ called DAC (DSMC Analysis Code). Simulations using the DSMC codes for the transitional flow regime are complemented with results from Navier-Stokes simulations for continuum conditions and results from free molecular analysis for collisionless flow. Navier-Stokes solutions are generated with the code of Gnoffo, ${ }^{15-17}$ called LAURA (Langley Aerothermodynamic Upwind Relaxation Algorithm).

Results are presented that show the sensitivity of the capsule aerodynamics to rarefaction for a Knudsen number range of 111 to 0.0003 , corresponding to an altitude range of 250 to $75 \mathrm{~km}$, and provide an indication of the agreement and consistency of the results obtained with different computational tools. Aerodynamic results as a function of angle of attack are presented for a transitional flow condition $(\mathrm{Kn}=0.06$, altitude $=$ $105 \mathrm{~km}$ ) along with the corresponding results as generated with free molecular (FM) and modified Newtonian $(\mathrm{MN})$ analyses. Also, the sensitivity of the aerodynamics in the transitional regime $(\mathrm{Kn}=0.06)$ is examined for a relative velocity range of 7.6 to $15 \mathrm{~km} / \mathrm{s}$. 


\section{Numerical Programs and Model Parameters}

\section{A. DSMC Analyses}

For the transitional rarefied flow conditions, two DSMC codes, DS3V (Version 2.4.01) and DAC (Version DAC97), were used to both generate the data and provide a check on the consistency of the results. The DS3V code of Bird ${ }^{9-11}$ is a general 3D code that provides both time-accurate unsteady flow and time-averaged steady flow simulations. In the current study, a scalar version of this program was used and all the present simulations were made by using a $3.2 \mathrm{GHz}$ personal computer with a memory of $2.0 \mathrm{~GB}$. The DAC program of LeBeau ${ }^{12-14}$ provides both scalar and parallel processing options. Parallel processing is accomplished by domain decomposition and the parallel version of DAC is employed in the current study. For both DSMC programs, the molecular collisions are simulated with the variable hard sphere molecular model. The Larsen-Borgnakke statistical model ${ }^{18}$ controls the energy exchange between kinetic and internal modes. All simulations are performed by using a five-species reacting air gas model while considering energy exchange between translation, rotational, and vibrational modes. Also, the surface is assumed to be noncatalytic and at a specified wall temperature. As for gas-surface interactions, they are assumed to be diffuse, with full energy accommodation.

The geometric size of the computational domain was varied with the degree of rarefaction of the freestream flow, since the influence of the body on the external flow at high Knudsen numbers extends outward a greater distance than is the case for a denser flow. Note that no attempt was made to capture the total extent of the flow field disturbance created by the capsule for the more rarefied conditions, because the disturbances tend to infinity as collisionless flow conditions are approached. The size of computational domains was similar, in most cases the same, for the two sets of DSMC simulations. The total number of cells within the computational domain was also a variable. Grid adaptations used in the DAC simulations targeted 10 simulated molecules per cell, while those in the DS3V simulations targeted either 8 or 30 (30 for the more rarefied conditions) molecules per collision cell.

An indicator of the resolution achieved in a DS3V simulation is given by the ratio of the mean collision separation between collision partners to the local mean free path $(m c s / m f p)$. Previous simulations ${ }^{6}$ for the Apollo capsule have demonstrated the importance and need to ensure that the value of this merit parameter be of order one or less throughout the flow domain to achieve cell resolved aerodynamics. If these guidelines are not met, the calculated results will be inaccurate.

For the DAC code, the user can implement a sequence of grid refinements of the two-level Cartesian grid such that the cell size is small in relation to the local mean free path. The current DAC simulations used between 0.3 and 256 million molecules, depending on the free-stream conditions, with the cell dimension less than the local mean free path except for the $100 \mathrm{~km}$ and $95 \mathrm{~km}$ conditions where the target was two mean free path resolution. Also, all of the DAC simulations used the nearest neighbor collision model, which enhances the cell resolution. For the DS3V computations, the total number of simulated molecules used ranged from 0.8 to 10 million. Both DSMC codes used the same unstructured surface definition for the Orion CM.

\section{B. Navier-Stokes Analyses}

Navier-Stokes solutions were computed with the LAURA computational fluid dynamics code. ${ }^{15-17}$ A threedimensional upwind-biased finite-volume structured grid solver, LAURA models perfect gas, equilibrium, or thermo-chemical non-equilibrium flow over vehicles at hypersonic conditions. The inviscid, thin-layer, or full NS governing equations are integrated to a steady state using either point- or line-relaxation. Roe's averaging ${ }^{19}$ with Harten's entropy fix ${ }^{20}$ from the first-order inviscid flux and Yee's Symmetric Total Variation Diminishing (TVD) limiter ${ }^{21}$ extend the first-order flux to second order. Second order central differences are used to construct the viscous fluxes. While multiple options exist within LAURA, those selected for this work result from a "best practices" effort under taken in support of the CEV Aerosciences Project (CAP) Team. The presented flight simulations used the full NS equations, a 7-species air model, assumed thermal non-equilibrium chemistry, and a radiative equilibrium wall condition with a constant emissivity of 0.85. Surface recombination was modeled with a fully catalytic condition: under this condition the atomic species are forced to their diatomic state at the wall, however if NO strikes the surface it remains NO. All simulations assumed laminar flow.

The volume grid consisted of 40 equally dimensioned blocks with a total of 2.2 million cells. At each 
surface point, 96 cells span the region from the wall to the outer boundary. In this surface normal direction, a grid adaptation procedure in LAURA insures a cell Reynolds number on the order of one at the wall, grid stretching values of approximately 1.2 or less, and an outer domain that is aligned with the bow shock. Grid adaptation occurs several times $(\approx 5)$ during the evolution of the solution. The NS simulations were performed using 20 dual-processor $2.8 \mathrm{GHz}$ Opteron workstations with one grid block assigned to each processor. Solutions were considered converged when surface heating everywhere on the forebody changed by less than 0.5 percent over 5000 iterations.

\section{Free Molecular and Newtonian Analyses}

The free molecular (FM) and modified Newtonian (MN) results were obtained with the DACFREE code of R. G. Wilmoth (private communication, July 2005). DACFREE computes aerodynamic forces and moments on arbitrary bodies using standard free molecular and modified Newtonian methods. This code can handle arbitrary geometries specified as an unstructured collection of triangles, and for the present study, the surface grid was the same as that used in the DSMC simulations.

\section{Conditions for Current Numerical Simulations}

The axisymmetric geometry for the Orion Crew Module used in the present study is shown in Fig. 2. The Orion capsule has a truncated spherical section, followed by a toroidal section, and then a conical frustum. When the pressures and shear stresses are integrated over the surface, the resultant force acts at the center-of-pressure $(\mathrm{cp})$ of the capsule; that is, the location about which the moment is zero. The total force vector is usually resolved into components, as shown in Fig. 3. Nomenclature used for the body (axial, $\mathrm{C}_{A}$, and normal, $\mathrm{C}_{N}$ ) and velocity (drag, $\mathrm{C}_{D}$, and lift, $\mathrm{C}_{L}$ ) oriented coordinates are as shown in Fig. 4 along with the sign convention for the moments about the nose, $\mathrm{C}_{m, 0}$, and center of gravity, $\mathrm{C}_{m, c g}$. Currently the center of gravity location is not known, but a test location has been specified as $1.3333 \mathrm{~m}$ aft of the nose of the spherical segment with a $0.2414 \mathrm{~m}$ offset as indicated in Figs. 2 and 3.

For the DSMC simulations, an unstructured surface grid (Figs. 4 and 5) is used to define the body surface, where the number of surface points and triangles are 4039 and 7922 , respectively. Note that the numerical simulations take advantage of the problem symmetry in that the flow is computed about only half of the capsule.

Free-stream atmospheric conditions are listed in Tables 1 and 2 and are based on the data of Jacchia ${ }^{22}$ (an exospheric temperature of $1200 \mathrm{~K}$ ) for altitudes of $90 \mathrm{~km}$ and above and on that of Ref. 23 for altitudes less than $90 \mathrm{~km}$. For the DSMC and DACFREE simulations, the surface temperatures are assumed to be uniformly distributed at the values listed in Tables 3,4 and 6, and are assigned based on the minimum value resulting from either the free-molecular radiative equilibrium heat transfer to the stagnation point or the radiative equilibrium temperature based on the stagnation point heating from the correlation of Sutton (Eq. 1 of Ref. 24). The effective radius for the Sutton correlation is $5.2939 \mathrm{~m}$, based on the procedure discussed in Ref. 25, page 265. The hard sphere, free-stream Knudsen numbers listed in Table 2 are based on the free-stream number density, a characteristic length of $5.0292 \mathrm{~m}$ (maximum capsule diameter), and a constant molecular diameter of $3.78 \times 10^{-10} \mathrm{~m}$.

\section{Results of Numerical Simulations}

The procedure followed in the current study for the Orion CM is almost identical to that conducted previously ${ }^{6,7}$ for the Apollo capsule. That is, several computational codes are used to provide aerodynamic data from hypersonic continuum to free molecular conditions, and with this data set one can extract information regarding the extent of the agreement achieved when using different codes, information regarding the bounds for reliable application of Navier-Stokes codes as the flow becomes rarefied, and the sensitivity of the aerodynamics to reentry velocities beyond that for entry from LEO conditions. Each of these aspects will be discussed for the Orion CM in the following sections. Two relevant findings from the Apollo results ${ }^{6}$ not covered herein will briefly be restated. First, NS solutions for a $85 \mathrm{~km}$ altitude and $9.6 \mathrm{~km} / \mathrm{s}$ set of conditions showed that the Apollo aerodynamics are insensitivite to the inclusion of ionized species in the gas model; consequently, the DSMC simulations with only five species (no ionized species) should be appropriate for simulating aerodynamics for high entry velocities with appreciable ionization present. Second, results of grid 
sensitivity studies using the DS3V code provided both qualitative and quantitative (comparison with NS solutions for altitudes as low as $85 \mathrm{~km}$ ) results, demonstrating the impact of cell resolution on aerodynamics, where the predicted drag, axial, and normal forces decrease in magnitude with cell refinement while the magnitude of the lift and lift-to-drag ratio increases with cell refinement. For the present study, cell resolution computations were performed with both DSMC codes where the qualitative behavior was the same as previously reported ${ }^{6}$ and will not be discussed further.

Data presented in Tables 3-9 and Figs. 5-17 provide a summary of results for the current study. First a comparison of results from the two DSMC codes is made (Figs. 5 and 6), highlighting the differences observed for drag, lift, and lift-to-drag ratio along with the manner in which the DSMC results approach the data generated assuming collisionless flow. Next, the DSMC data sets are integrated with the NS results, overlapping and extending to lower altitudes the aerodynamic data base such that it covers a large Knudsen number range (111 to 0.0003). These results are presented in Figs. 7-9 as a function of Knudsen number and provide additional information regarding code comparisons and the altitude or Knudsen boundaries for realistic application of NS codes. Data shown in Figs. 10-16 provide information regarding the dependance of Orion's aerodynamics on angle of attack, how it is influenced by the extent of rarefaction, and implications regarding static stability. Results presented in Fig. 17 demonstrates the sensitivity of Orion's aerodynamics to variations in relative velocity for a range of conditions that are inclusive of LEO, Lunar, and Mars return missions.

\section{A. Comparison of Results Generated with Two DSMC Codes for Rarefied Transitional Flow}

Figures 5 and 6 provide a comparison of the results obtained with DS3V and DAC for drag, lift, and lift-todrag coefficients, shown as a function of altitude. Free molecular results for several free-stream conditions are included (Fig. 5) to highlight the small changes that occur due to variations in free-stream gas composition (Table 2) and wall temperature (Tables 6), and to provide an indication where the DSMC and DACFREE results overlap, occurring at approximately $250 \mathrm{~km}$ altitude $(\mathrm{Kn}=111)$. Results from the two DSMC codes are seen to be in good qualitative agreement (Fig. 5), but quantitatively the agreement is only fair to good (Fig. 6). As shown in Fig. 6, the agreement is good for drag with differences of about $1 \%$ or less. However, for lift and L/D, the maximum differences are approximately 10\%, much larger than expected and occurring at sufficiently rarefied flow conditions such that the computational requirements to achieve cell resolved simulations are not demanding. It should be noted that the differences previously observed ${ }^{7}$ between these two codes for the Apollo simulations (for altitudes between 110 and $100 \mathrm{~km}$, differences of $4 \%$ for drag and $7 \%$ for lift) has been noticeably reduced for the current Orion simulations after a coding correction was made to the DS3V code. Additional efforts should be made to identify the reason for the differences currently evident (Fig. 6) in the results from the two codes, with a goal of achieving differences of no more that $1 \%$, as is evident in the current simulations for only the 105 and $110 \mathrm{~km}$ cases.

\section{B. Aerodynamic Results Spanning Continuum to Free Molecular Conditions}

Data presented in Figs. 7-9 provide fundamental aerodynamic results for a representative Orion entry from LEO, highlighting the significance of rarefaction effects for the larger Kn number conditions and the continuing importance of viscous effects for the lower Knudsen number conditions. The overall trends are such that the magnitude of the drag, axial, and normal force coefficients increase while the lift and liftto-drag coefficients decrease with increasing rarefaction; consistent with the trends evident from previous numerical simulations, such as that for the Aeroassist Flight Experiment (AFE) vehicle ${ }^{26}$ and other capsule and reentry configurations. ${ }^{27,28}$

As evident in Fig. 7, the lift coefficient approaches a small value for the large Knudsen number conditions, This occurs because the friction contribution to lift is a negative quantity and its contribution increases with rarefaction, while the pressure contribution is positive and relatively constant with increasing rarefaction, as is demonstrated in Ref. 26 for the AFE.

With the DAC code providing general parallel processing capability, lower Knudsen number cases can be simulated at cell resolved conditions, than is the case for DS3V. Current DAC simulations (Table 4) have been made for altitudes as low as $95 \mathrm{~km}$, or a Knudsen number of 0.01 . The NS solutions were generated for altitudes higher than one could expect reliable results, so as to provide some insight into the nature of the breakdown of the continuum simulations when applied to the more rarefied conditions, particularly so without surface slip and temperature jump boundary conditions, as was the case for the current LAURA 
calculations. Comparisons of the DSMC and NS results suggest that the overall agreement in aerodynamics is fair even at $95 \mathrm{~km}$, with the trends of the NS and DSMC data sets suggesting that even a better overlap could be achieved between 85 and $95 \mathrm{~km}$. Clearly, the NS and DSMC data sets show that the two very different numerical methods are producing similar and reasonably consistent results in the $95 \mathrm{~km}$ altitude range (Kn of 0.011).

Figure 9 details the movement of the center of pressure and the corresponding moment coefficient about the center of gravity as a function of Knudsen number. As the capsule descends from 250 to $75 \mathrm{~km}$, the center of pressure experiences a substantial translation as it moves from a position forward of the center of gravity to one well aft. The corresponding change in the moment coefficient is from a relatively large negative value to essentially a zero value.

For the higher altitude cases, the wall temperatures that have been specified are quite low, possibly too low. So the DACFREE results presented in Table 6 for the highest altitude case includes additional results of calculations with wall temperature values in excess of the currently used value of $144 \mathrm{~K}$. The effect of increasing the wall temperature is generally small, with the lift coefficient experiencing the most obvious effect. Note that all the force and moment coefficients are shown (Table 6) to increase in magnitude with increasing wall temperature.

\section{Aerodynamics as a Function of Angle of Incidence and the Influence of Rarefaction}

Figures 10 though 16 and Table 7 present data that show the dependence of the Orion CM aerodynamics to variations in angle of attack for a relative velocity of $7.6 \mathrm{~km} / \mathrm{s}$. Included are results from the DACFREE code that provide the collisionless (FM) and modified Newtonian (MN) values generated at 250 and $75 \mathrm{~km}$ altitude, respectively. Also, results generated with the DS3V code for an altitude of $105 \mathrm{~km}(\mathrm{Kn}=0.06)$ are included. Consequently, the data includes free molecular, transitional, and continuum results, where the continuum proxie is the MN results. How well the MN serves as a proxie for NS is indicated by the ratios presented in Table 8, where the force and moment coefficient values generated by MN are ratioed to those generated by LAURA for the -26 deg angle of attack condition. This comparison (Table 8 ) shows that the MN results generally agree with the NS results to within $12 \%$ or better for the current set of conditions.

For the drag coefficients (Fig. 10), we see that the transitional values are always bounded on the high side by the FM values and on the low side by the MN values. Figures 11 and 12 once again demonstrate the small value of lift and L/D experienced at the more rarefied conditions and the current results show the lift coefficient to have a maximum value at an angle of attack (Fig. 11) of about -35 deg, whereas, L/D experiences a maximum value near $-50 \mathrm{deg}$ (Fig. 12) and decreases slightly with increasing rarefaction. Of probably more significant importance is the values for the moment coefficients about the offset center of gravity as displayed in Fig. 15. Recall that a static trim location is one where the moment coefficient has a value of zero and the slope of the moment curve is negative with increasing angle of attack. Three static trim locations are evident for the FM results, only one for the DS3V results at $105 \mathrm{~km}$ located near -165 $\mathrm{deg}$, and only one for the MN results near $-29 \mathrm{deg}$. Consequently, the Orion CM flying at -26 deg angle of atttack would be statically unstable for much, if not all of the transitional flow regime, a result not that uncommon $^{29,30}$ for capsules in the transitional rarefied regime, the same general features as were found ${ }^{6,7}$ for the Apollo capsule.

\section{Effect of Free-Stream Velocity on Aerodynamics}

To examine the effects of free-stream velocity variations, simulations were made for the Orion CM at an altitude of $105 \mathrm{~km}$ and -26 degrees angle of attack for 5 free-stream velocities ranging from 7.6 to 15 $\mathrm{km} / \mathrm{s}$ (Table 9). The $15 \mathrm{~km} / \mathrm{s}$ velocity is representative of the upper bounds for a Mars return mission. Consequently, this range of entry velocities is inclusive of that for reentry from LEO, lunar return, and Mars return missions. Results of the simulations for variations in free-stream velocity show (Table 9 and Fig. 17) that the changes in the aerodynamic coefficients with increasing velocity are similar to those incurred with increasing rarefaction; that is, the magnitude of the drag, axial, and normal force coefficients increases with increasing free-stream velocity while the magnitude of the lift and lift-to-drag ratio coefficients decrease with increasing velocity. These findings are consistent with the correlations demonstrated by Wilhite et al. ${ }^{31}$ (Fig. 7, p 172) for the Shuttle Orbiter axial-force coefficients as a function of a viscous correlation parameter. 


\section{Concluding Remarks}

A computational study of hypersonic flow over a current version of the proposed Orion Crew Module (CM) is made by using direct simulation Monte Carlo (DSMC), Navier-Stokes, and free molecular analyses. Numerical simulations are made for Earth entry conditions, similar to those that would be experienced by Orion for reentry from low Earth orbit. Simulations are made for altitudes of 250 to $75 \mathrm{~km}$ (Knudsen numbers from 11 to 0.0003 ), free-stream velocities of 7.6 to $15 \mathrm{~km} / \mathrm{s}$, and a complete range of angles of attack. Results of the simulations show the effect of rarefaction, angle of attack, and entry velocity on the aerodynamic forces and moments, and the variability in results obtained when using different computational codes.

Significant findings of the present study are: (1) the overlap of the DSMC and NS simulations for the $95 \mathrm{~km}$ (Knudsen number of 0.01) are shown to be reasonably close for all aerodynamic parameters, (2) the comparison of the two DSMC codes, DS3V and DAC, show good qualitative agreement but larger quantitative differences (a maximum of $10 \%$ in lift-to-drag) than expected for much of the transitional flow regime, (3) the Orion CM is statically unstable for much of the rarefied flow regime, the same finding as for Apollo, and (4) changes in the aerodynamic coefficients with increasing velocity have the same trend as that for increasing rarefaction.

\section{Acknowledgments}

The authors acknowledge the assistance of the following individuals: Victor Lessard of Genex Systems for providing the unstructured surface grid, Graeme Bird of G.A.B. Consulting Pty Ltd and Richard Wilmoth of CRAFT Tech, Inc. for assistances with the DS3V and DACFREE codes, respectively, and Richard Wheless of NCI Information Systems for assisting with the graphics.

\section{References}

${ }^{1}$ Lee, D. B., "Apollo Experience Report-Aerothermodynamics Evaluation," NASA TN D-6843, June 1972.

${ }^{2}$ Lee, D. B. and Goodrich, W. D., "The Aerothermodynamic Environment of the Apollo Command Module During Superorbital Entry," NASA TN D-6792, April 1972.

${ }^{3}$ Lee, D. B., Bertin, J. J., and Goodrich, W. D., "Heat-Transfer Rate and Pressure Measurements Obtained During Apollo Orbital Entries," NASA TN D-6028, April 1970.

${ }^{4}$ Hillje, E. R., "Entry Flight Aerodynamics from Apollo Mission AS-202," NASA TN D-4185, October 1967.

${ }^{5}$ Anon, "Aerodynamic Data Manual for Project Apollo (North American Aviation, Inc.)", NASA-CR-82907, October 1965.

${ }^{6}$ Moss, J. N., Glass, C. E., and Greene, F. A., "DSMC Simulations of Apollo Capsule Aerodynamics for Hypersonic Rarefied Conditions," AIAA Paper 2006-3577, June 2006.

${ }^{7}$ Moss, J. N., Glass, C. E., and Greene, F. A., "Blunt Body Aerodynamics for Hypersonic Low Density Flows," Paper presented at the 25th International Symposium on Rarefied Gas Dynamics, St. Petersburg, Russia, July 21-28, 2006.

${ }^{8}$ Padilla, J. F., and Boyd, I. D., "Assessment of Rarefied Hypersonic Aerodynamics Modeling and Windtunnel Data," AIAA Paper 2006-3390, June 2006.

${ }^{9}$ Bird, G. A., Visual DSMC Program for Three-Dimensional Flows. The DS3V Program User's Guide, Version 2.2, March 2006.

${ }^{10}$ Bird, G. A., "The DS2V/3V Program Suite for DSMC Calculations," Rarefied Gas Dynamics, 24th International Symposium on Rarefied Gas Dynamics, edited by M. Capitelli, American Institute of Physics, Vol. 762, New York, 2005, pp.541-546.

${ }^{11}$ Bird, G. A., Molecular Gas Dynamics and the Direct Simulation of Gas Flows. Oxford: Clarendon Press, 1994.

${ }^{12}$ LeBeau, G. J., "A Parallel Implementation of the Direct Simulation Monte Carlo Method," Computer Methods in Applied Mechanics and Engineering, Parallel Computational Methods for Flow Simulation and Modeling, Vol. 174, 1999, pp. $319-337$. AIAA Paper 2006-3577, June 2006.

${ }^{13}$ LeBeau, G. J., and Lumpkin, F. E., III, "Application Highlights of the DSMC Analysis Code (DAC) Software for Simulating Rarefied Flows," Computer Methods in Applied Mechanics and Engineering, Vol. 191, Dec. 2001, pp. 595-609.

${ }^{14}$ Boyles, K. A., LeBeau, G. J.,Lumpkin, F. E., III, and Blanchard, R. C., "The use of Virtual Sub-Cells in DSMC Analysis of Orbiter Aerodynamics at High Altitudes Upon Reentry," AIAA Paper 2003-1030, January 2003.

${ }^{15}$ Gnoffo, P. A., "An Upwind-Biased, Point-Implicit Algorithm for Viscous, Compressible Perfect-Gas Flows," NASA TP2953, Feb. 1990.

${ }^{16}$ Gnoffo, P. A., Gupta, R. N., and Shinn, J. L, "Equations and Physical Models for Hypersonic Air Flows in Thermal and Chemical Nonequilibrium," NASA TP-2867, Feb. 1989.

${ }^{17}$ Cheatwood, F. M., and Gnoffo, P. A., "User's Manual for the Langley Aerothermodynamic Upwind Relaxation Algorithm (LAURA)," NASA TM 4674, April 1996.

${ }^{18}$ Borgnakke, C., and Larsen, P. S., "Statistical Collision Model for Monte Carlo Simulation of Polyatomic Gas Mixture," Journal of Computational Physics, Vol. 18, No. 4, 1975, pp. 405-420. 
${ }^{19}$ Roe, P. L., "Approximate Riemann Solvers, Parameter Vectors and Difference Schemes," Journal of Computational Physics, Vol. 43, No. 12, 1981, pp. 357-372.

${ }^{20}$ Harten, A., "High Resolution Schemes for Hyperbolic Conservation Laws," Journal of Computational Physics, Vol. 49, No. 3, 1983, pp. 357-393.

${ }^{21}$ Yee, H. C., "On Symmetric and Upwind TVD Schemes," NASA TM-88325, Feb. 1990.

${ }^{22}$ Jacchia, L. G., "Thermospheric Temperature, Density, and Composition: New Models," Smithsonian Astrophysical Observatory, Cambridge, MA, Special Rept. 375, March 1977.

${ }^{23}$ Anon, "U. S. Standard Atmosphere, 1962," Dec. 1962.

${ }^{24}$ Sutton, K., "Air Radiation Revisited," AIAA Paper 84-1733, June 1984.

${ }^{25}$ Bertin, J. J., Hypersonic Aerothermodynamics, AIAA Education Series, Washington, DC, 1994.

${ }^{26}$ Celenligil, M. C., Moss, J. N., and Blanchard, R. C., "Three-Dimensional Rarefied Flow Simulations for the Aeroassist Flight Experiment Vehicle," AIAA Journal, Vol. 29, No. 1, 1991, pp. 52-57.

${ }^{27}$ Ivanov, M. S., Markelov, G. N., Gimelshein, S. F., Mishina, L. V., Krylov, A. N., and Grechko, N. V., "High-Altitude Capsule Aerodynamics with Real Gas Effects," Journal of Spacecraft and Rockets, Vol. 35, No. 1, 1998, pp. 16-22.

${ }^{28}$ Vashchenkov, P., Kashkovsky, A. Ivanov, M., "Numerical Analysis of High Altitude Aerodynamics of Reentry Vehicles," AIAA Paper 2005-3409, May 2005.

${ }^{29}$ Wilmoth, R. G., Mitcheltree, R. A., and Moss, J. N., "Low-Density Aerothermodynamics of the Stardust Sample Return Capsule," Journal of Spacecraft and Rockets, Vol. 36, No.3, 1999, pp. 436-441.

${ }^{30}$ Moss, J. N., Blanchard, R. C., Wilmoth, R. G., and Braun, R. D., "Mars Pathfinder Rarefied Aerodynamics: Computations and Measurements," Journal of Spacecraft and Rockets, Vol. 36, No. 3, 1999, pp. 330-339.

${ }^{31}$ Wilhite, A. W., Arrington, J. P., and McCandless, R. S., "Performance Aerodynamics of Aeroassisted Orbital Transfer Vehicles," Progress in Astronautics and Aeronautics, Vol. 96, Thermal Design of Aeroassisted Orbital Transfer Vehicles, edited by H.F. Nelson, AIAA, New York, 1985, pp. 165-185.

Table 1. Free-stream conditions

\begin{tabular}{ccccc}
\hline \hline Altitude, $\mathrm{km}$ & $n_{\infty}, \mathrm{m}^{-3}$ & $\rho_{\infty}, \mathrm{kg} / \mathrm{m}^{3}$ & $T_{\infty}, \mathrm{K}$ & Molecular weight \\
\hline 250 & $2.8210 \times 10^{15}$ & $9.4248 \times 10^{-11}$ & 1124 & 20.121 \\
220 & $5.4532 \times 10^{15}$ & $1.9180 \times 10^{-10}$ & 1077 & 21.182 \\
200 & $8.9996 \times 10^{15}$ & $3.2829 \times 10^{-10}$ & 1026 & 21.970 \\
180 & $1.6146 \times 10^{16}$ & $6.1220 \times 10^{-10}$ & 947 & 22.832 \\
170 & $2.2702 \times 10^{16}$ & $8.7777 \times 10^{-10}$ & 892 & 23.286 \\
160 & $3.3470 \times 10^{16}$ & $1.3207 \times 10^{-9}$ & 822 & 23.765 \\
150 & $5.3055 \times 10^{16}$ & $2.1383 \times 10^{-9}$ & 733 & 24.273 \\
145 & $6.9352 \times 10^{16}$ & $2.8265 \times 10^{-9}$ & 682 & 24.545 \\
140 & $9.3526 \times 10^{16}$ & $3.8548 \times 10^{-9}$ & 625 & 24.823 \\
135 & $1.3149 \times 10^{17}$ & $5.4862 \times 10^{-9}$ & 564 & 25.127 \\
130 & $1.9429 \times 10^{17}$ & $8.2075 \times 10^{-9}$ & 500 & 25.442 \\
125 & $3.0598 \times 10^{17}$ & $1.3100 \times 10^{-8}$ & 433 & 25.783 \\
120 & $5.2128 \times 10^{17}$ & $2.2642 \times 10^{-8}$ & 368 & 26.159 \\
115 & $9.8562 \times 10^{17}$ & $4.3575 \times 10^{-8}$ & 304 & 26.626 \\
110 & $2.1246 \times 10^{18}$ & $9.6068 \times 10^{-8}$ & 247 & 27.232 \\
105 & $4.9759 \times 10^{18}$ & $2.3004 \times 10^{-7}$ & 211 & 27.843 \\
100 & $1.1898 \times 10^{19}$ & $5.5824 \times 10^{-7}$ & 194 & 28.258 \\
95 & $2.9047 \times 10^{19}$ & $1.3800 \times 10^{-6}$ & 189 & 28.613 \\
90 & $7.0755 \times 10^{19}$ & $3.3848 \times 10^{-6}$ & 188 & 28.888 \\
85 & $1.6540 \times 10^{20}$ & $7.9550 \times 10^{-6}$ & 181 & 28.960 \\
75 & $9.0130 \times 10^{20}$ & $4.3350 \times 10^{-5}$ & 200 & 28.960 \\
\hline \hline
\end{tabular}


Table 2. Atmospheric composition and Knudsen numbers for reentry conditions

\begin{tabular}{crccc}
\hline \hline Altitude, $\mathrm{km}$ & $\mathrm{X}_{O 2}$ & $\mathrm{X}_{N 2}$ & $\mathrm{X}_{O}$ & $\mathrm{Kn}_{\infty, D, H S}$ \\
\hline 250 & 0.01801 & 0.31886 & 0.66313 & 111.0 \\
220 & 0.02526 & 0.39751 & 0.57723 & 57.44 \\
200 & 0.03146 & 0.45476 & 0.51378 & 34.80 \\
180 & 0.03908 & 0.51635 & 0.44457 & 19.40 \\
170 & 0.04354 & 0.54820 & 0.40826 & 13.80 \\
160 & 0.04868 & 0.58121 & 0.37011 & 9.36 \\
155 & 0.05149 & 0.59800 & 0.35051 & 7.51 \\
150 & 0.05461 & 0.61557 & 0.32982 & 5.90 \\
145 & 0.05794 & 0.63379 & 0.30828 & 4.52 \\
140 & 0.06181 & 0.65173 & 0.28646 & 3.35 \\
135 & 0.06593 & 0.67158 & 0.26248 & 2.38 \\
130 & 0.07089 & 0.69113 & 0.23799 & 1.61 \\
125 & 0.07679 & 0.71171 & 0.21150 & 1.02 \\
120 & 0.08451 & 0.73271 & 0.18278 & 0.601 \\
115 & 0.09779 & 0.75386 & 0.14835 & 0.318 \\
110 & 0.12323 & 0.77042 & 0.10635 & 0.147 \\
105 & 0.15280 & 0.78187 & 0.06533 & 0.0629 \\
100 & 0.17682 & 0.78440 & 0.03877 & 0.0263 \\
95 & 0.19719 & 0.78685 & 0.01595 & 0.0108 \\
85 & 0.23720 & 0.76280 & 0.00000 & 0.0019 \\
75 & 0.23720 & 0.76280 & 0.00000 & 0.0003 \\
\hline \hline
\end{tabular}


Table 3. Orion CM aerodynamics for $-26^{\circ}$ incidence and $7.6 \mathrm{~km} / \mathrm{s}$ as computed with DS3V

\begin{tabular}{lccccccccc}
\hline \hline Alt., km & $T_{W}, \mathrm{~K}$ & $C_{A}$ & $C_{N}$ & $C_{m, 0}$ & $x_{c p}, \mathrm{~m}$ & $C_{m, c g}$ & $C_{D}$ & $C_{L}$ & $L / D$ \\
\hline 250 & 144 & 1.714 & -0.798 & 0.117 & 0.734 & -0.177 & 1.890 & 0.034 & 0.018 \\
220 & 172 & 1.711 & -0.793 & 0.117 & 0.740 & -0.176 & 1.886 & 0.038 & 0.020 \\
200 & 197 & 1.710 & -0.787 & 0.116 & 0.744 & -0.174 & 1.882 & 0.042 & 0.022 \\
180 & 230 & 1.701 & -0.776 & 0.116 & 0.750 & -0.172 & 1.869 & 0.048 & 0.026 \\
170 & 251 & 1.695 & -0.767 & 0.116 & 0.759 & -0.169 & 1.860 & 0.053 & 0.029 \\
160 & 278 & 1.686 & -0.755 & 0.116 & 0.770 & -0.166 & 1.846 & 0.061 & 0.033 \\
150 & 314 & 1.671 & -0.736 & 0.116 & 0.792 & -0.160 & 1.825 & 0.071 & 0.039 \\
145 & 337 & 1.666 & -0.725 & 0.115 & 0.801 & -0.157 & 1.815 & 0.079 & 0.044 \\
140 & 364 & 1.658 & -0.710 & 0.115 & 0.814 & -0.153 & 1.801 & 0.088 & 0.049 \\
135 & 398 & 1.651 & -0.693 & 0.115 & 0.834 & -0.148 & 1.787 & 0.101 & 0.057 \\
130 & 440 & 1.643 & -0.671 & 0.114 & 0.858 & -0.142 & 1.770 & 0.117 & 0.066 \\
125 & 494 & 1.638 & -0.645 & 0.114 & 0.889 & -0.136 & 1.755 & 0.138 & 0.079 \\
120 & 567 & 1.629 & -0.601 & 0.114 & 0.955 & -0.123 & 1.727 & 0.174 & 0.101 \\
115 & 618 & 1.613 & -0.538 & 0.115 & 1.078 & -0.105 & 1.685 & 0.224 & 0.133 \\
110 & 682 & 1.555 & -0.437 & 0.115 & 1.329 & -0.0750 & 1.589 & 0.289 & 0.182 \\
105 & 760 & 1.465 & -0.327 & 0.114 & 1.752 & -0.0431 & 1.460 & 0.348 & 0.239 \\
100 & 849 & 1.379 & -0.250 & 0.107 & 2.159 & -0.0251 & 1.349 & 0.380 & 0.281 \\
\hline \hline
\end{tabular}


Table 4. Orion CM aerodynamics for $-26^{\circ}$ incidence and $7.6 \mathrm{~km} / \mathrm{s}$ as computed with DAC

\begin{tabular}{lccccccccc}
\hline \hline Alt., km & $T_{W}, \mathrm{~K}$ & $C_{A}$ & $C_{N}$ & $C_{m, 0}$ & $x_{c p}, \mathrm{~m}$ & $C_{m, c g}$ & $C_{D}$ & $C_{L}$ & $L / D$ \\
\hline 250 & 144 & 1.710 & -0.795 & 0.116 & 0.736 & -0.177 & 1.886 & 0.035 & 0.019 \\
220 & 172 & 1.708 & -0.789 & 0.116 & 0.737 & -0.176 & 1.881 & 0.039 & 0.021 \\
200 & 197 & 1.705 & -0.783 & 0.116 & 0.746 & -0.173 & 1.875 & 0.044 & 0.023 \\
180 & 230 & 1.697 & -0.770 & 0.116 & 0.758 & -0.170 & 1.863 & 0.051 & 0.028 \\
170 & 251 & 1.687 & -0.759 & 0.115 & 0.763 & -0.167 & 1.849 & 0.058 & 0.031 \\
160 & 278 & 1.677 & -0.745 & 0.115 & 0.777 & -0.163 & 1.834 & 0.066 & 0.036 \\
150 & 314 & 1.664 & -0.725 & 0.115 & 0.797 & -0.157 & 1.813 & 0.078 & 0.043 \\
145 & 337 & 1.656 & -0.712 & 0.115 & 0.812 & -0.153 & 1.800 & 0.086 & 0.048 \\
140 & 364 & 1.646 & -0.696 & 0.115 & 0.829 & -0.149 & 1.785 & 0.096 & 0.054 \\
135 & 398 & 1.638 & -0.677 & 0.114 & 0.849 & -0.144 & 1.768 & 0.110 & 0.062 \\
130 & 440 & 1.632 & -0.656 & 0.114 & 0.871 & -0.139 & 1.755 & 0.126 & 0.072 \\
125 & 494 & 1.629 & -0.626 & 0.113 & 0.907 & -0.131 & 1.738 & 0.152 & 0.087 \\
120 & 567 & 1.616 & -0.584 & 0.113 & 0.974 & -0.119 & 1.709 & 0.184 & 0.107 \\
115 & 618 & 1.595 & -0.523 & 0.115 & 1.102 & -0.101 & 1.663 & 0.229 & 0.138 \\
110 & 682 & 1.542 & -0.431 & 0.115 & 1.344 & -0.0731 & 1.575 & 0.288 & 0.183 \\
105 & 760 & 1.455 & -0.323 & 0.114 & 1.779 & -0.0412 & 1.449 & 0.347 & 0.240 \\
100 & 849 & 1.370 & -0.239 & 0.106 & 2.227 & -0.0233 & 1.336 & 0.386 & 0.289 \\
95 & 951 & 1.319 & -0.185 & 0.098 & 2.675 & -0.0141 & 1.266 & 0.412 & 0.326 \\
\hline \hline
\end{tabular}

Table 5. Orion CM aerodynamics for $-26^{\circ}$ incidence and $7.6 \mathrm{~km} / \mathrm{s}$ as computed with LAURA

\begin{tabular}{lccccccccc}
\hline \hline Alt., km & $\mathrm{Stag}^{*} . T_{W}, \mathrm{~K}$ & $C_{A}$ & $C_{N}$ & $C_{m, 0}$ & $x_{c p}, \mathrm{~m}$ & $C_{m, c g}$ & $C_{D}$ & $C_{L}$ & $L / D$ \\
\hline 105 & 950 & 1.726 & -0.461 & 0.169 & 1.849 & -0.0356 & 1.753 & 0.342 & 0.195 \\
100 & 1025 & 1.440 & -0.271 & 0.120 & 2.224 & -0.0211 & 1.420 & 0.390 & 0.275 \\
95 & 1115 & 1.342 & -0.194 & 0.103 & 2.667 & -0.0131 & 1.291 & 0.414 & 0.321 \\
85 & 1340 & 1.290 & -0.131 & 0.092 & 3.538 & -0.0046 & 1.217 & 0.448 & 0.368 \\
75 & 1630 & 1.281 & -0.112 & 0.091 & 4.078 & -0.0003 & 1.200 & 0.461 & 0.384 \\
\hline \hline
\end{tabular}

* Stagnation wall temperatures for a radiative equilibrium wall boundry with 0.85 emissivity. 
Table 6. Orion CM aerodynamics for $-26^{\circ}$ incidence and $7.6 \mathrm{~km} / \mathrm{s}$ as computed with DACFREE

\begin{tabular}{cccccccccc}
\hline \hline Alt., km & $T_{W}, \mathrm{~K}$ & $C_{A}$ & $C_{N}$ & $C_{m, 0}$ & $x_{c p}, \mathrm{~m}$ & $C_{m, c g}$ & $C_{D}$ & $C_{L}$ & $L / D$ \\
\hline 100 & 849 & 1.774 & -0.804 & 0.118 & 0.738 & -0.180 & 1.945 & 0.0535 & 0.0275 \\
150 & 314 & 1.731 & -0.803 & 0.116 & 0.730 & -0.179 & 1.908 & 0.0377 & 0.0198 \\
200 & 197 & 1.722 & -0.803 & 0.116 & 0.730 & -0.179 & 1.900 & 0.0336 & 0.0177 \\
220 & 172 & 1.720 & -0.803 & 0.116 & 0.730 & -0.179 & 1.898 & 0.0326 & 0.0172 \\
250 & 144 & 1.718 & -0.803 & 0.116 & 0.730 & -0.179 & 1.896 & 0.0314 & 0.0166 \\
250 & 200 & 1.729 & -0.804 & 0.117 & 0.732 & -0.179 & 1.907 & 0.0359 & 0.0188 \\
250 & 300 & 1.747 & -0.805 & 0.118 & 0.735 & -0.180 & 1.923 & 0.0427 & 0.0222 \\
250 & 400 & 1.762 & -0.805 & 0.118 & 0.737 & -0.180 & 1.936 & 0.0484 & 0.0250 \\
\hline \hline
\end{tabular}


Table 7. DS3V results for Orion CM aerodynamics as a function of incidence $\left(V_{\infty}=7.6 \mathrm{~km} / \mathrm{s}\right.$ and Alt. $\left.=105 \mathrm{~km}\right)$

\begin{tabular}{ccccccccc}
\hline \hline$\alpha, \mathrm{deg}$ & $C_{A}$ & $C_{N}$ & $C_{m, 0}$ & $C_{D}$ & $C_{L}$ & $L / D$ & $C_{m, c g}$ & $C_{m, c g}^{*}$ \\
\hline 0 & 1.709 & 0.000 & 0.000 & 1.709 & 0.000 & 0.000 & -0.082 & -0.082 \\
-5 & 1.700 & -0.064 & 0.023 & 1.699 & 0.085 & 0.050 & -0.075 & -0.088 \\
-10 & 1.672 & -0.128 & 0.046 & 1.668 & 0.165 & 0.099 & -0.068 & -0.093 \\
-15 & 1.626 & -0.191 & 0.069 & 1.620 & 0.237 & 0.146 & -0.060 & -0.096 \\
-20 & 1.562 & -0.254 & 0.090 & 1.5551 & 0.296 & 0.190 & -0.052 & -0.098 \\
-26 & 1.469 & -0.327 & 0.114 & 1.464 & 0.350 & 0.239 & -0.043 & -0.098 \\
-30 & 1.389 & -0.375 & 0.129 & 1.390 & 0.369 & 0.266 & -0.037 & -0.096 \\
-35 & 1.284 & -0.435 & 0.147 & 1.301 & 0.380 & 0.292 & -0.030 & -0.093 \\
-40 & 1.171 & -0.495 & 0.165 & 1.215 & 0.373 & 0.307 & -0.023 & -0.090 \\
-45 & 1.051 & -0.558 & 0.182 & 1.137 & 0.348 & 0.306 & -0.016 & -0.085 \\
-50 & 0.924 & -0.621 & 0.199 & 1.070 & 0.309 & 0.288 & -0.010 & -0.078 \\
-60 & 0.656 & -0.744 & 0.225 & 0.972 & 0.196 & 0.202 & -0.004 & -0.059 \\
-75 & 0.235 & -0.876 & 0.237 & 0.907 & 0.001 & 0.001 & -0.007 & -0.016 \\
-90 & -0.148 & -0.918 & 0.218 & 0.918 & -0.148 & -0.161 & -0.018 & -0.033 \\
-100 & -0.349 & -0.913 & 0.199 & 0.960 & -0.185 & -0.192 & -0.026 & 0.059 \\
-110 & -0.513 & -0.909 & 0.186 & 1.030 & -0.171 & -0.166 & -0.030 & 0.079 \\
-120 & -0.665 & -0.899 & 0.179 & 1.111 & -0.126 & -0.113 & -0.028 & 0.091 \\
-130 & -0.820 & -0.869 & 0.169 & 1.193 & -0.069 & -0.058 & -0.022 & 0.101 \\
-140 & -0.975 & -0.799 & 0.146 & 1.261 & -0.014 & -0.011 & -0.019 & 0.112 \\
-150 & -1.114 & -0.676 & 0.109 & 1.303 & 0.028 & 0.022 & -0.017 & 0.124 \\
-155 & -1.171 & -0.592 & 0.086 & 1.312 & 0.042 & 0.032 & -0.015 & 0.127 \\
-160 & -1.217 & -0.495 & 0.064 & 1.313 & 0.049 & 0.037 & -0.009 & 0.126 \\
-170 & -1.278 & -0.264 & 0.027 & 1.304 & 0.038 & 0.029 & 0.018 & 0.105 \\
-175 & -1.292 & -0.134 & 0.012 & 1.299 & 0.021 & 0.016 & 0.039 & 0.085 \\
-180 & -1.297 & 0.000 & 0.000 & 1.297 & 0.000 & 0.000 & 0.062 & 0.062 \\
\hline \hline
\end{tabular}

* The moment coefficient for the corresponding positive angle of attack.

Table 8. Ratio of modified Newtonian (MN) to LAURA Navier-Stokes results for Orion CM at $75 \mathrm{~km}$ and $\alpha=-\mathbf{2 6} \mathrm{deg}$

\begin{tabular}{ccccccc}
\hline \hline$C_{A}$ & $C_{N}$ & $C_{m, 0}$ & $C_{D}$ & $C_{L}$ & $L / D$ & $C_{m, c g}$ \\
\hline 1.04 & 0.88 & 0.91 & 1.03 & 1.07 & 1.04 & $-0.0071 /-0.0003$ \\
\hline \hline
\end{tabular}


Table 9. Sensitivity of aerodynamics to velocity for $-\mathbf{2 6}^{\circ}$ incidence and an altitude of $105 \mathrm{~km}$ (DS3V results)

\begin{tabular}{cccccccccc}
\hline \hline$V_{\infty}, \mathrm{km} / \mathrm{s}$ & $T_{W}, \mathrm{~K}$ & $C_{A}$ & $C_{N}$ & $C_{m, 0}$ & $x_{c p}, \mathrm{~m}$ & $C_{m, c g}$ & $C_{D}$ & $C_{L}$ & $L / D$ \\
\hline 7.6 & 760 & 1.465 & -0.327 & 0.114 & 1.752 & -0.0431 & 1.460 & 0.349 & 0.239 \\
9.2 & 877 & 1.477 & -0.337 & 0.114 & 1.701 & -0.0463 & 1.475 & 0.344 & 0.233 \\
10.7 & 983 & 1.485 & -0.348 & 0.114 & 1.654 & -0.0491 & 1.487 & 0.338 & 0.227 \\
12.3 & 1091 & 1.489 & -0.358 & 0.114 & 1.608 & -0.0519 & 1.495 & 0.331 & 0.221 \\
15.0 & 1266 & 1.495 & -0.371 & 0.114 & 1.548 & -0.0559 & 1.506 & 0.322 & 0.214 \\
\hline \hline
\end{tabular}




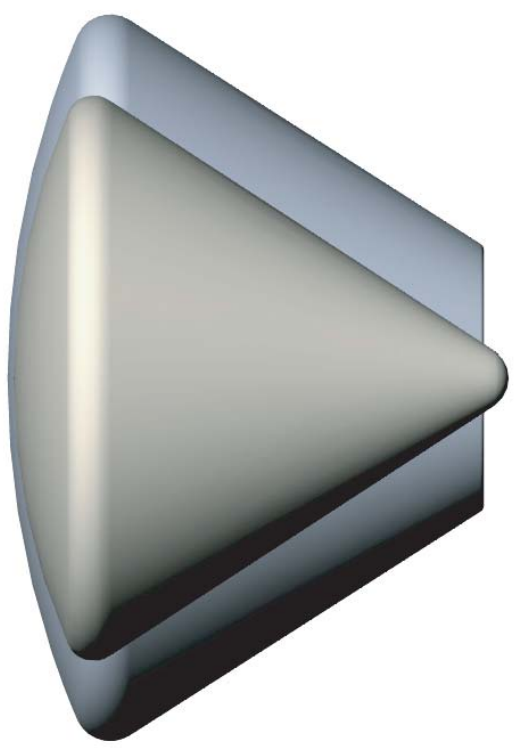

Figure 1. Relative size of the larger Orion Crew Module to the Apollo Command Module.

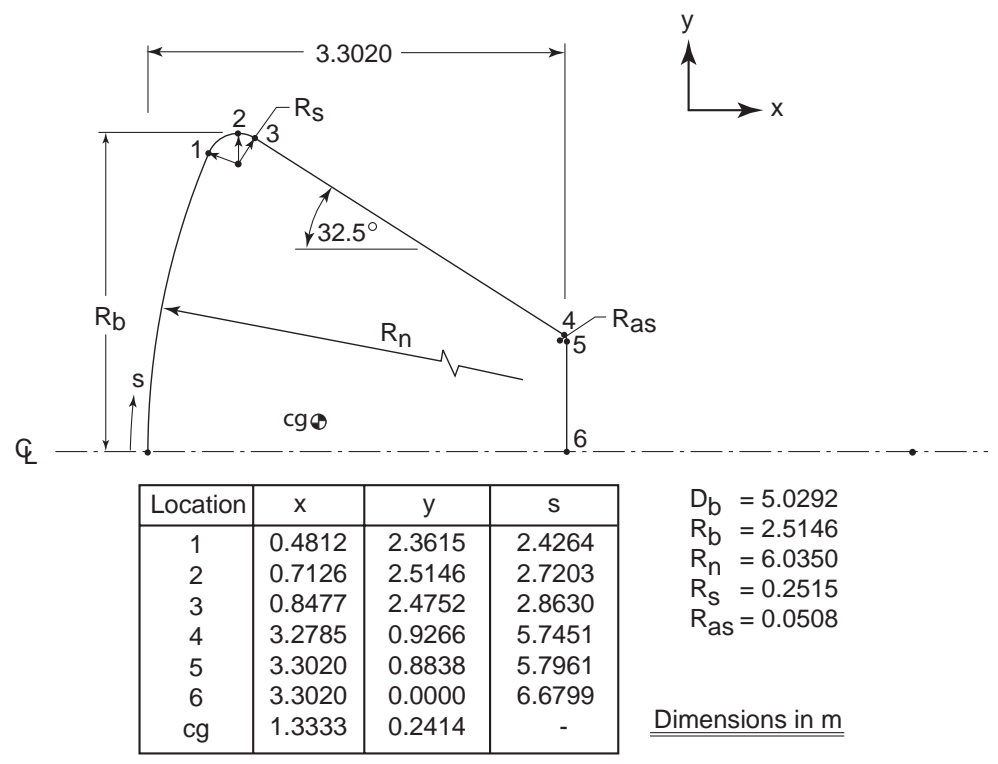

Figure 2. Outer mold line of the Orion CM used in the present work. 


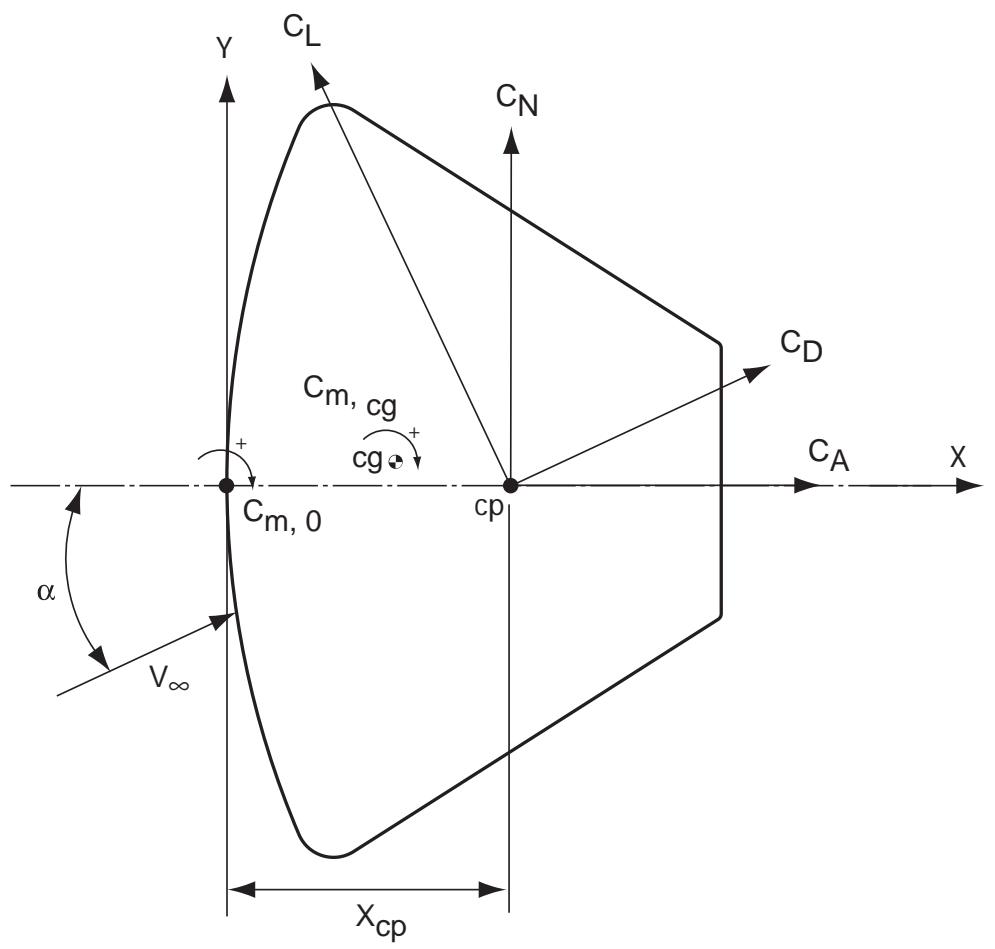

Figure 3. Nomenclature for aerodynamic forces in the pitch plane.

16 of 24

American Institute of Aeronautics and Astronautics Paper 2006-8081 


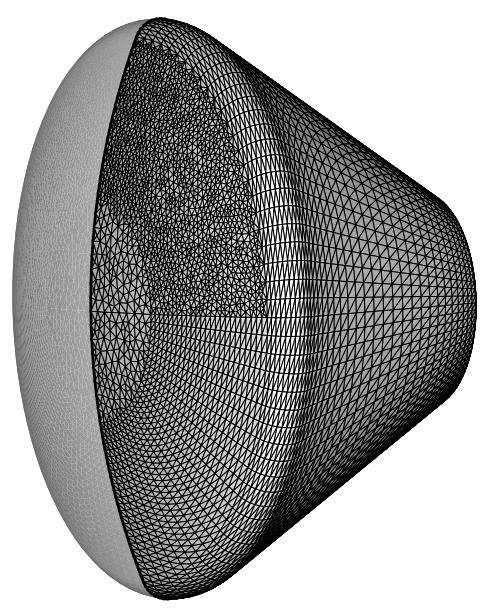

(a) Frontal view .

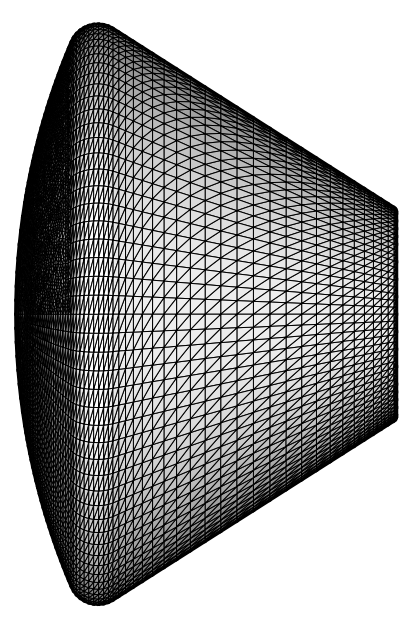

(b) Side view.

Figure 4. Orion CM unstructured body grid used in present DSMC simulations. 


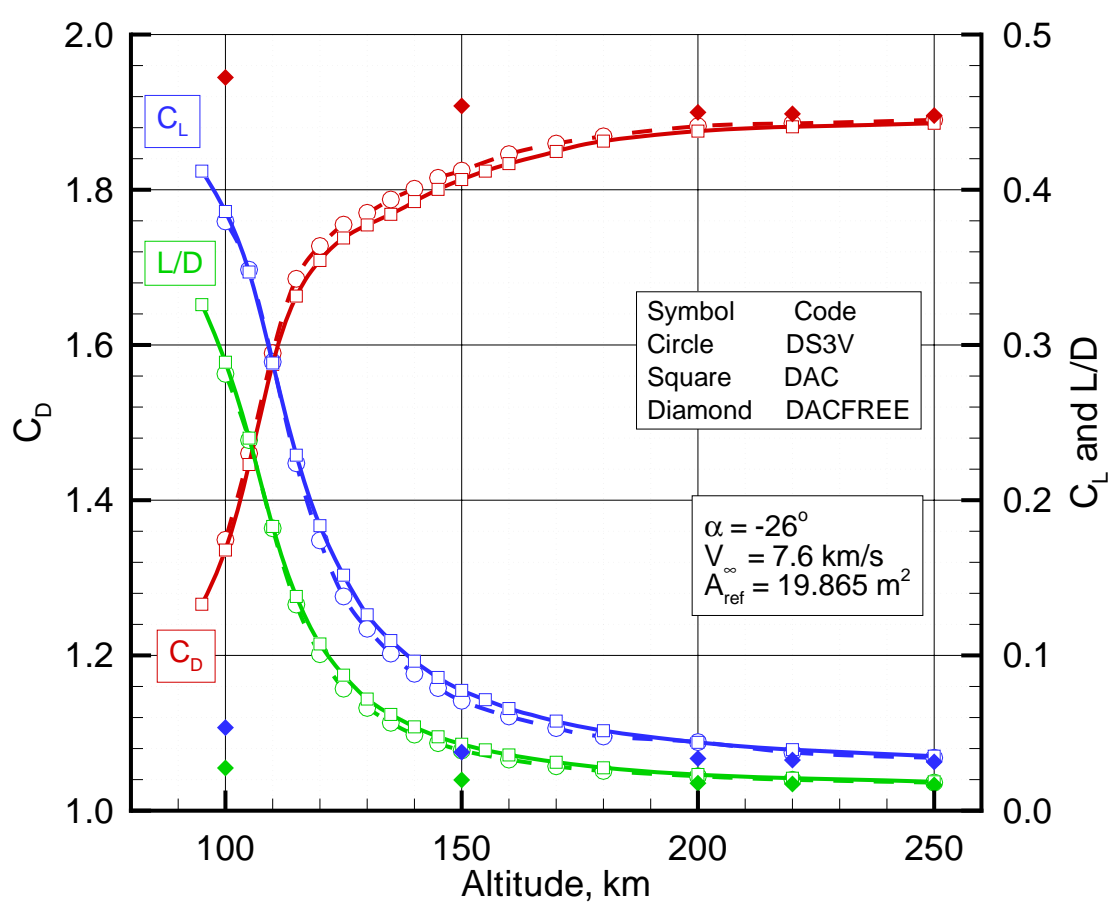

Figure 5. Orion CM aerodynamics as a function of altitude-DSMC and free molecular values (DACFREE).

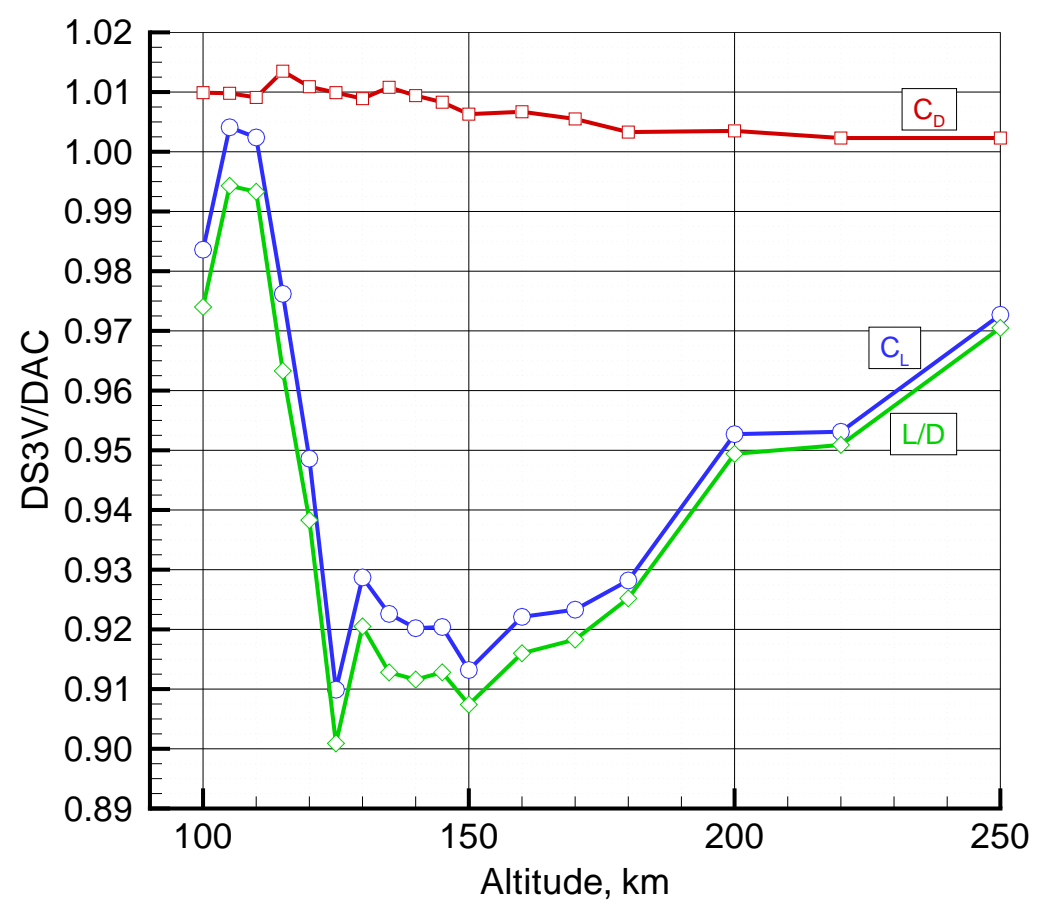

Figure 6. Ratio of DS3V to DAC values for Orion drag, lift, and lift-to-drag coefficients. 


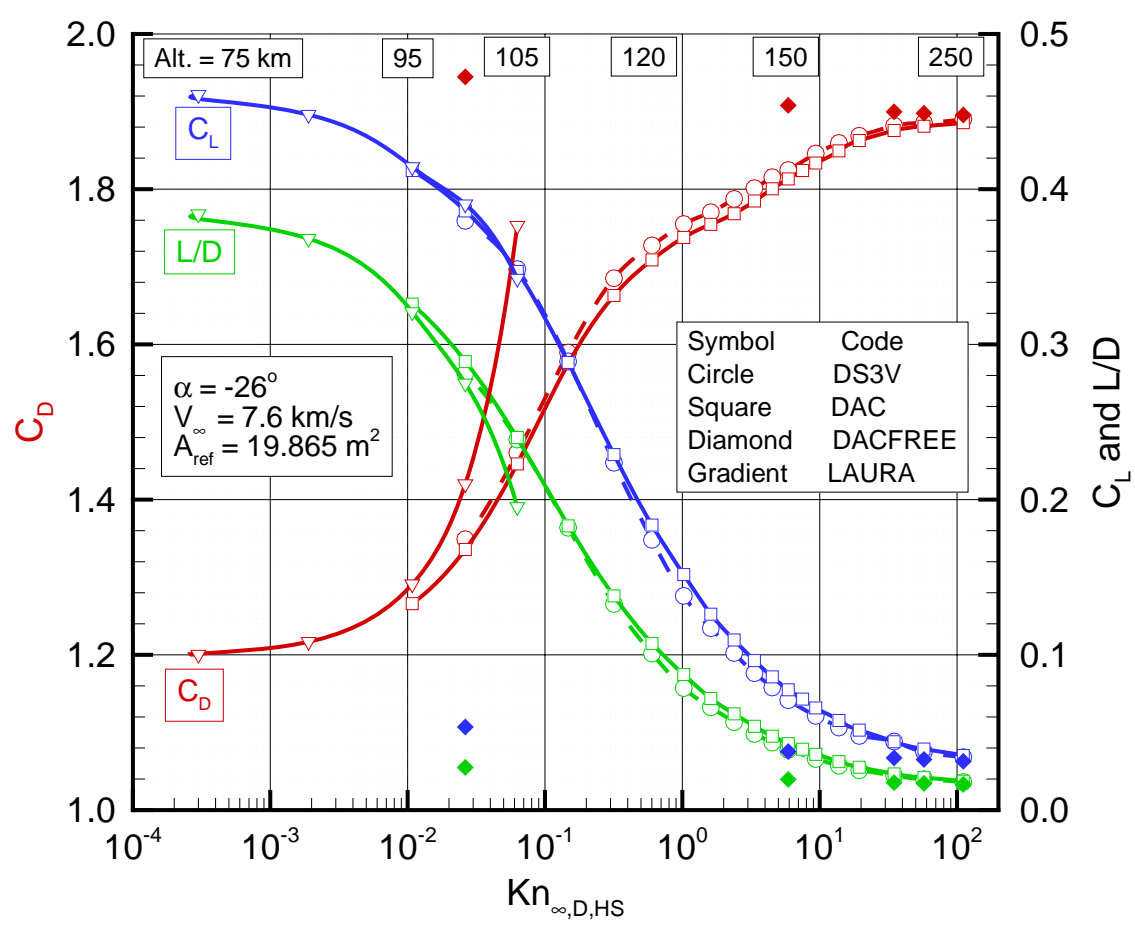

Figure 7. Orion CM drag, lift, and lift-to-drag coefficients.

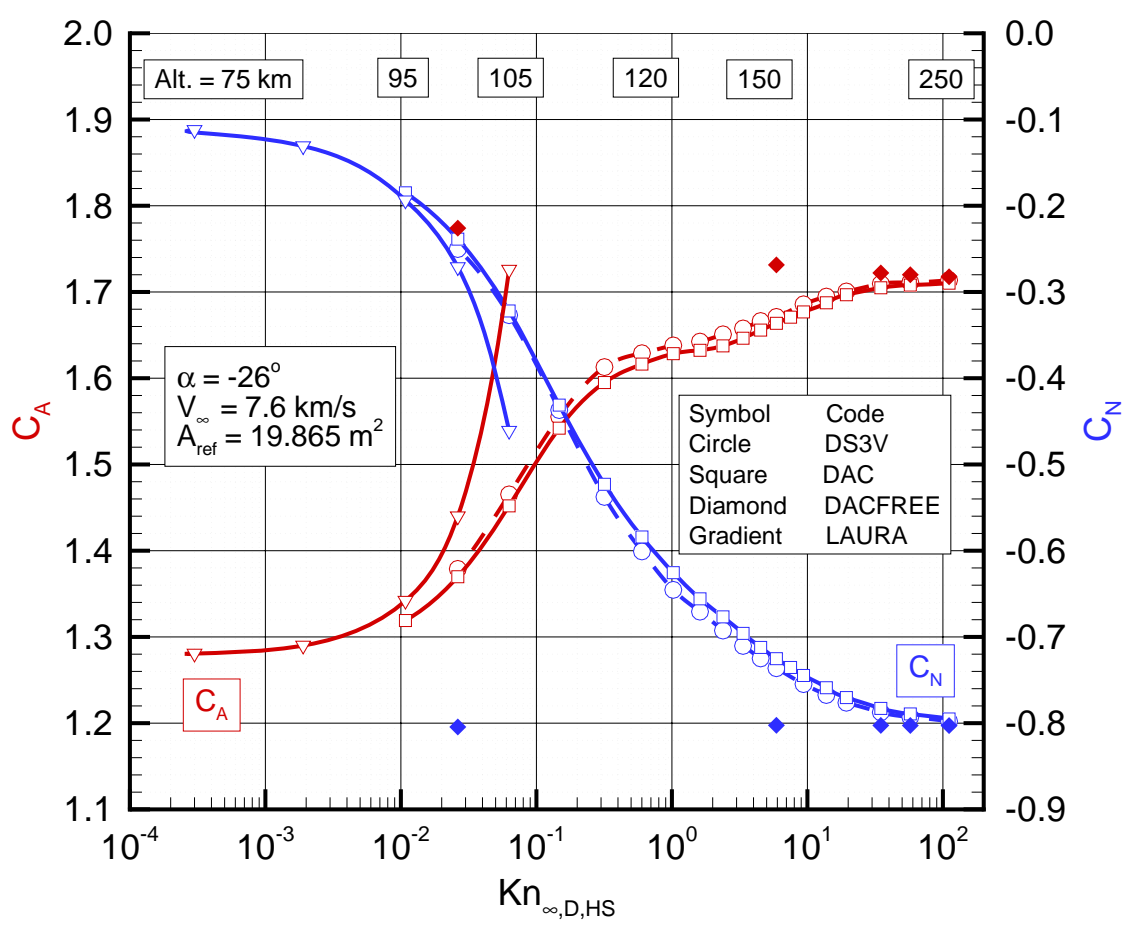

Figure 8. Orion CM axial and normal force coefficients. 


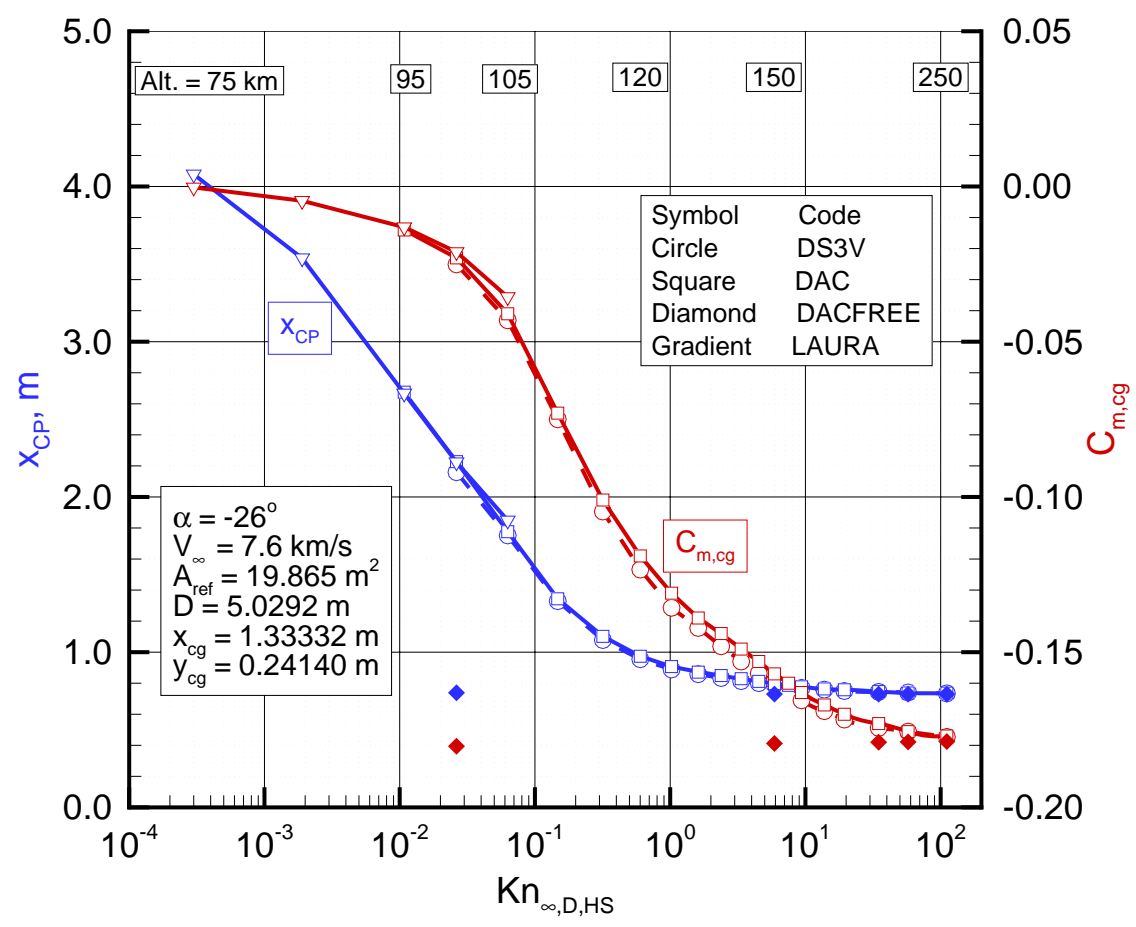

Figure 9. Orion center of pressure location and moment coefficient about center of gravity.

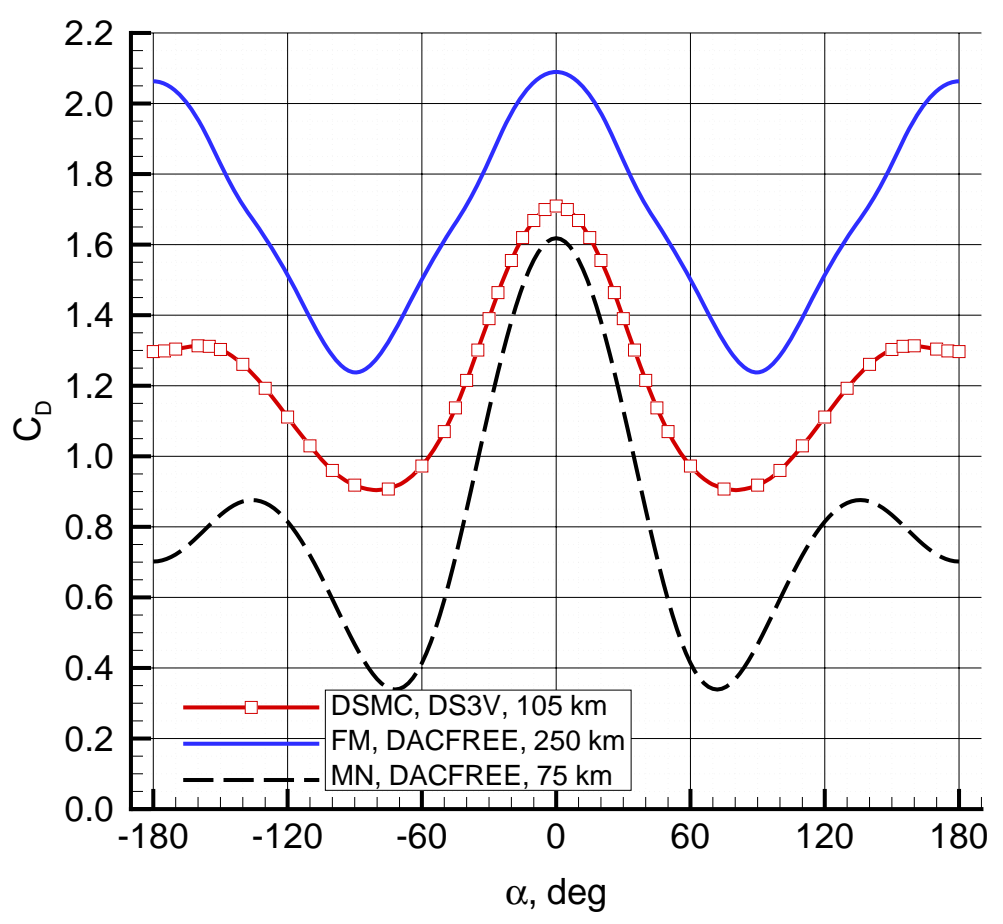

Figure 10. Effect of rarefaction on Orion CM drag coefficient. 


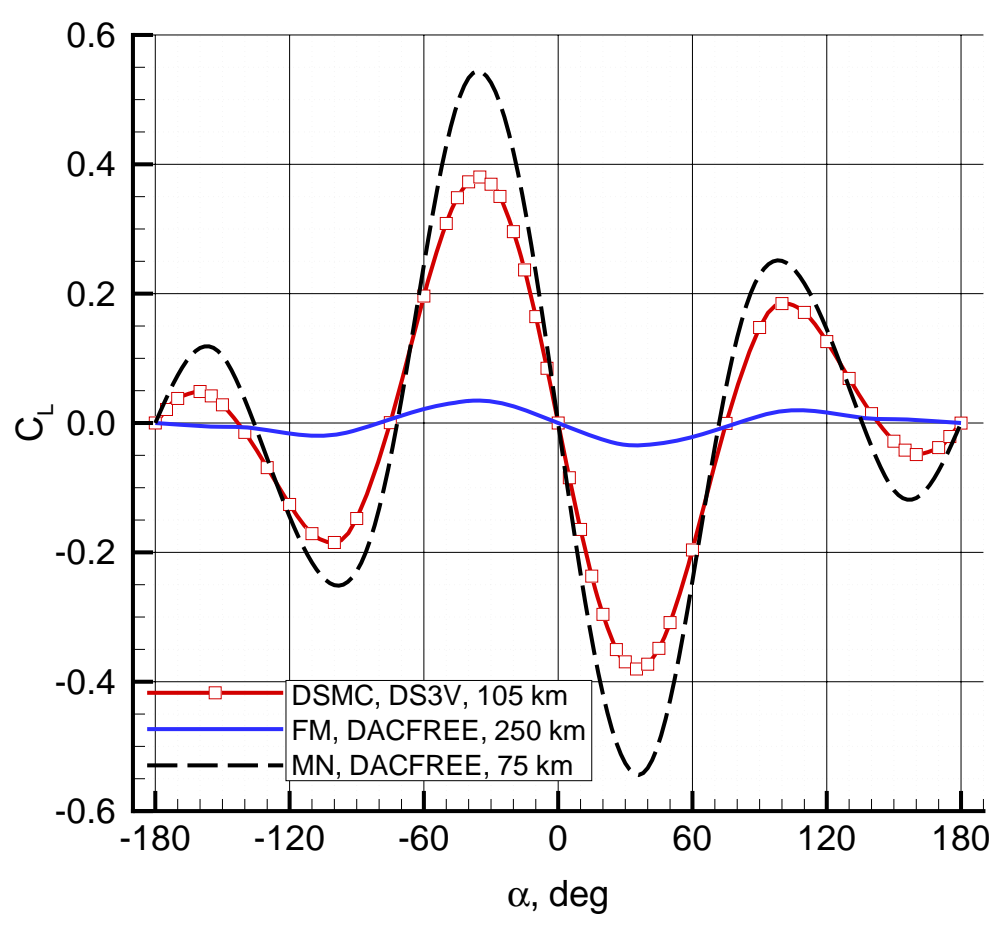

Figure 11. Effect of rarefaction on Orion CM lift coefficient.

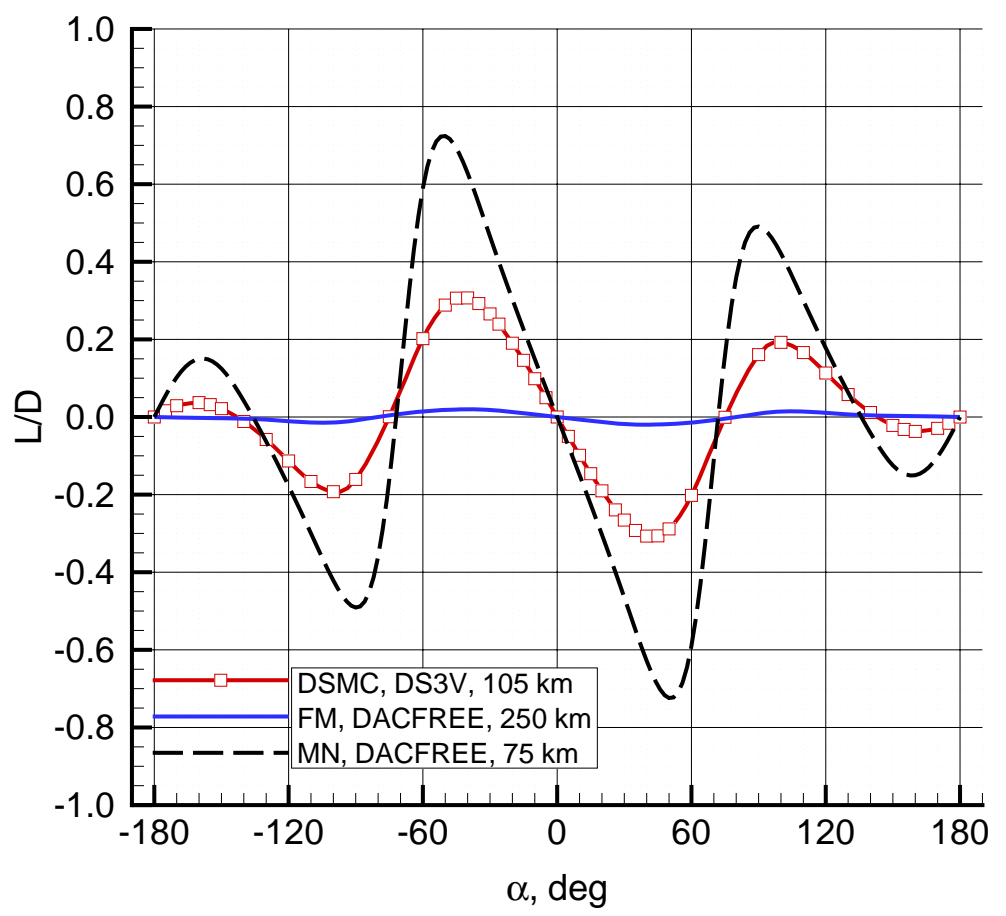

Figure 12. Effect of rarefaction on Orion CM lift-to-drag coefficient. 


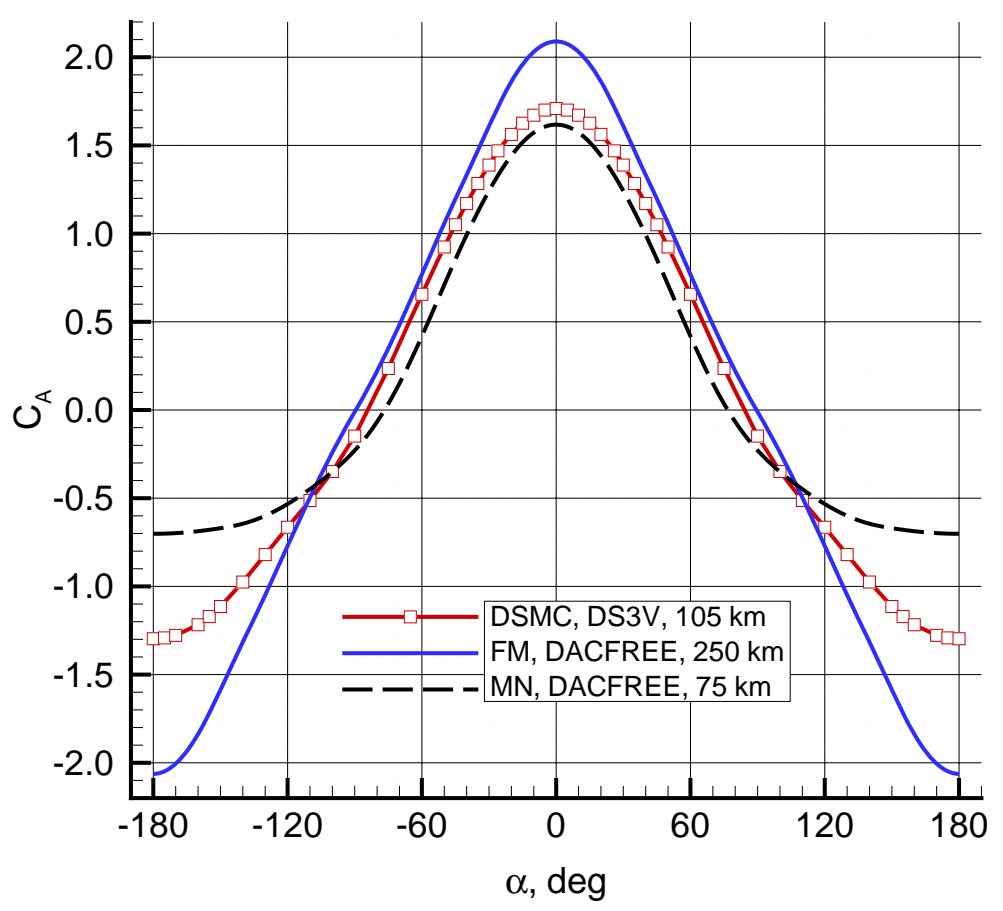

Figure 13. Effect of rarefaction on Orion CM axial force coefficient.

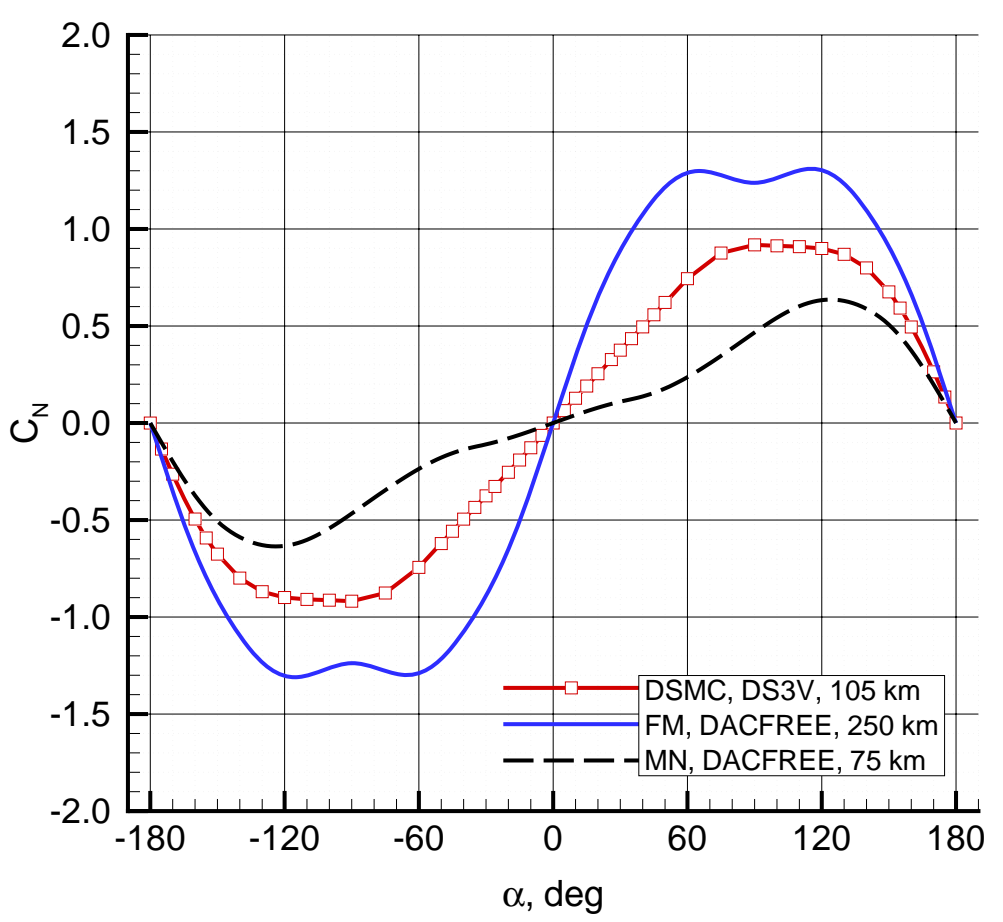

Figure 14. Effect of rarefaction on Orion CM normal force coefficient. 


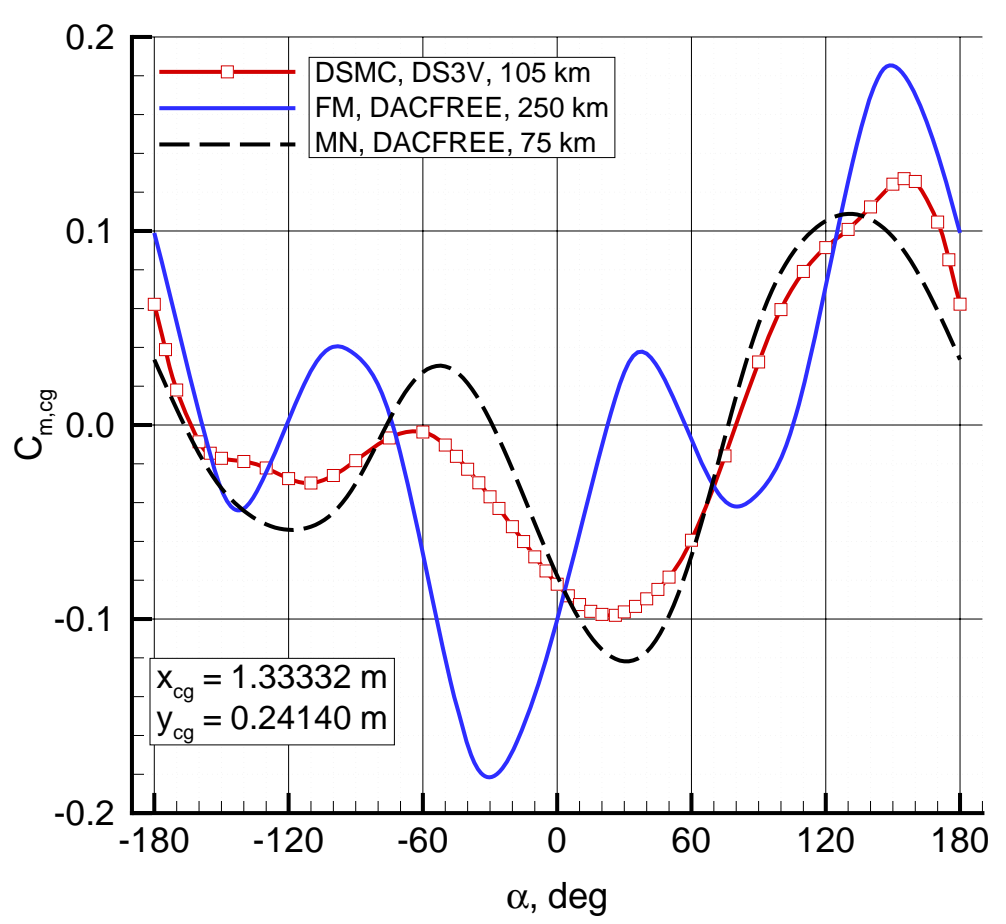

Figure 15. Effect of rarefaction on Orion CM moment coefficient about reference center of gravity.

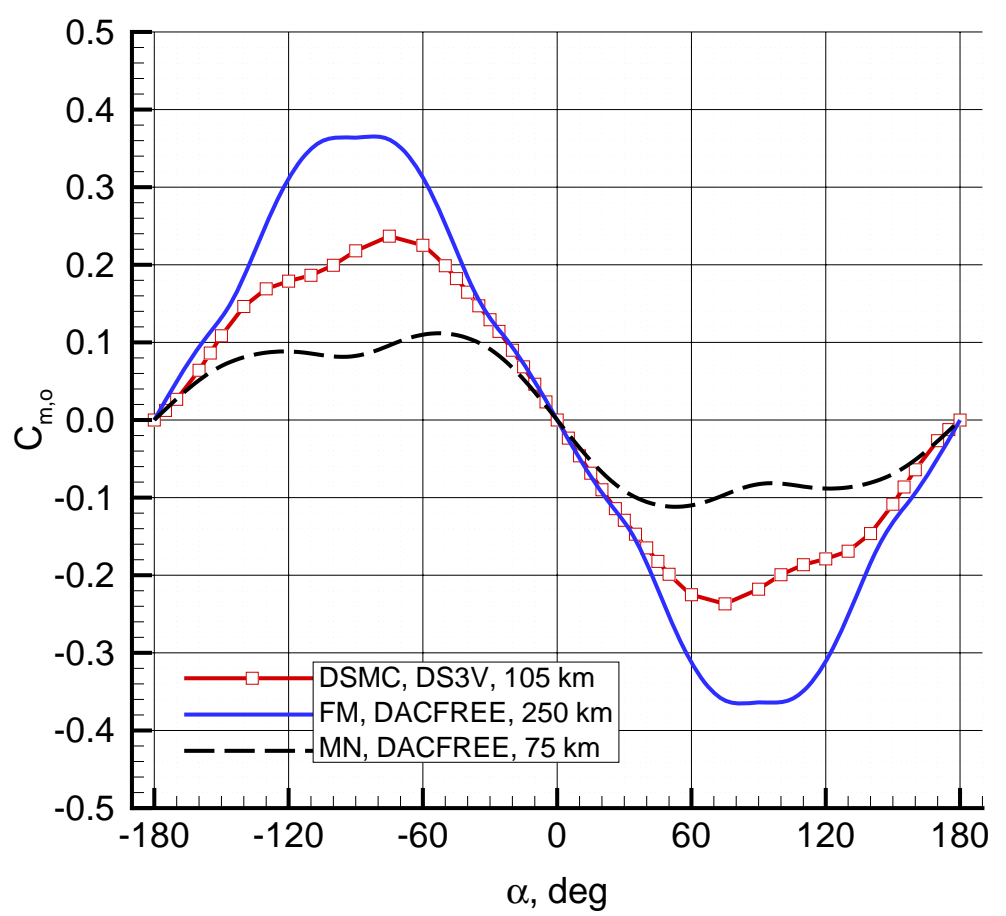

Figure 16. Effect of rarefaction on Orion CM moment coefficient with respect to the nose. 


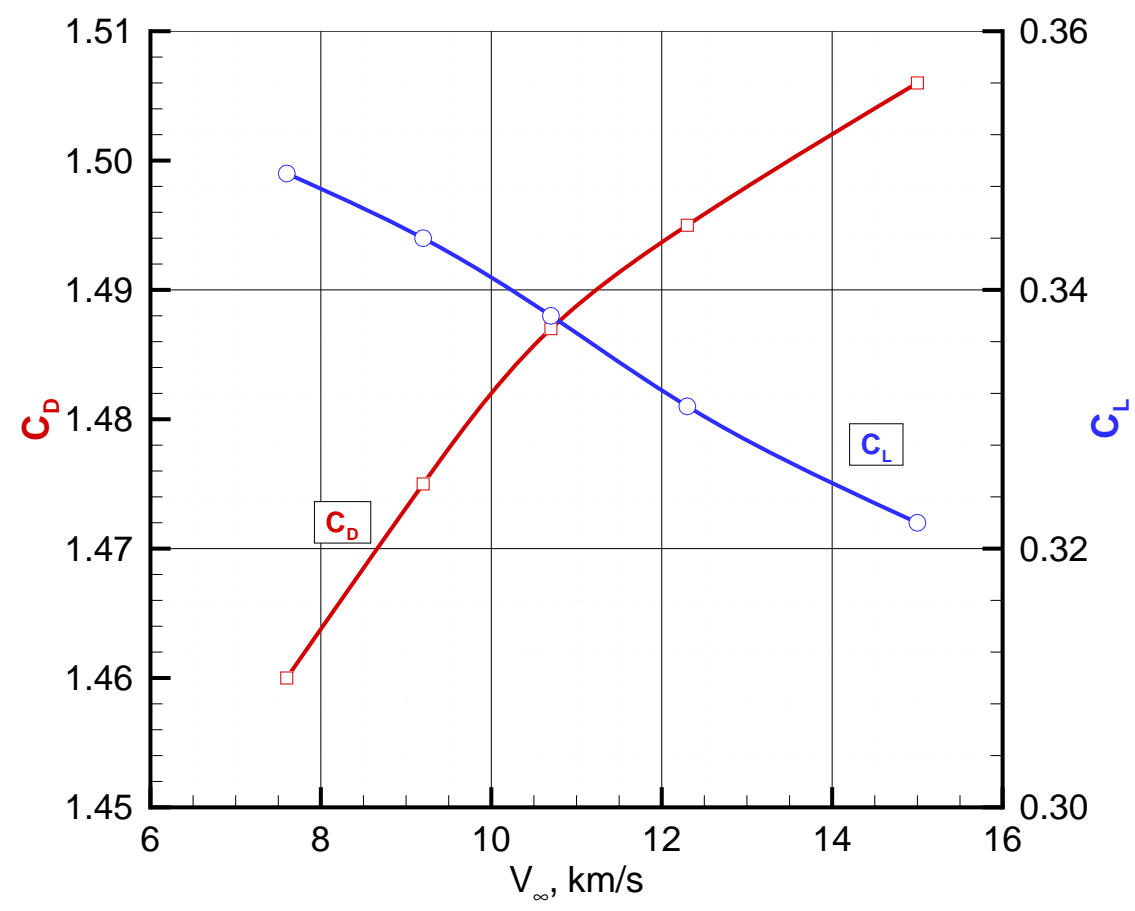

(a) Drag and lift coefficients.

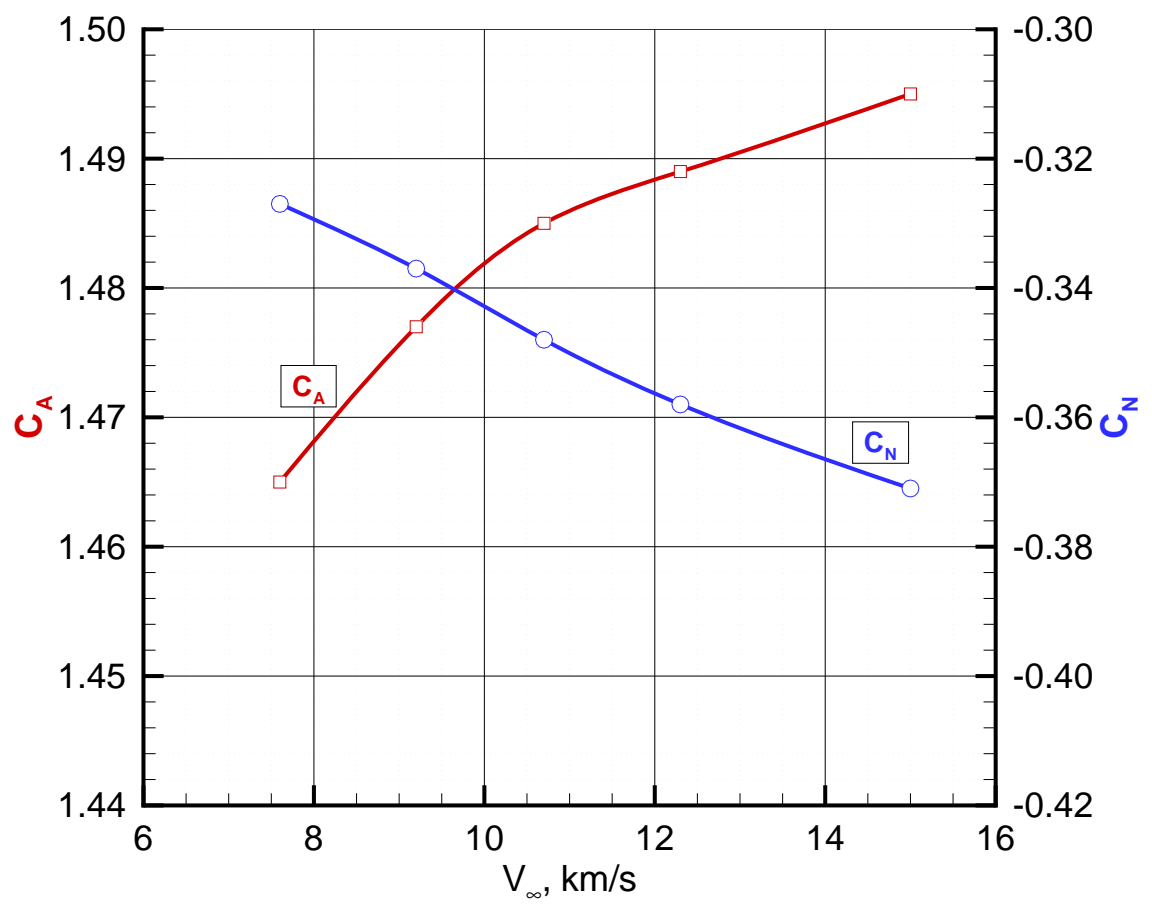

(b) Axial and normal coefficients.

Figure 17. Sensitivity of aerodynamic coefficients to free-stream velocity at $105 \mathrm{~km}$ and $\alpha=-26 \mathrm{deg}$ (DS3V results). 24 of 24 